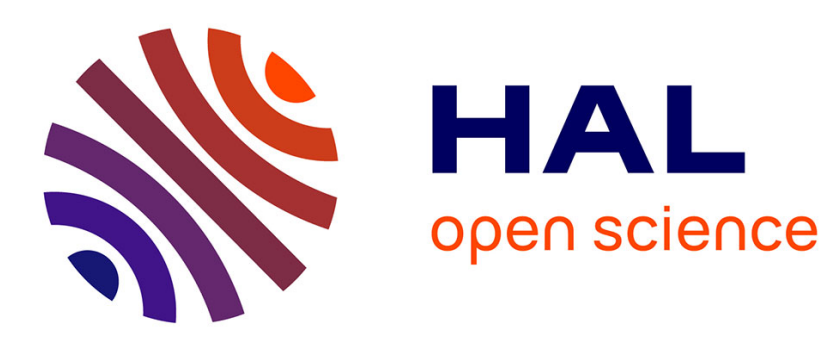

\title{
Beyond Imperviousness: The Role of Antecedent Wetness in Runoff Generation in Urbanized Catchments
}

Mohamed Saadi, Ludovic Oudin, Pierre Ribstein

\section{To cite this version:}

Mohamed Saadi, Ludovic Oudin, Pierre Ribstein. Beyond Imperviousness: The Role of Antecedent Wetness in Runoff Generation in Urbanized Catchments. Water Resources Research, 2020, 56 (11), 10.1029/2020WR028060 . hal-03104575

\section{HAL Id: hal-03104575 \\ https://hal.sorbonne-universite.fr/hal-03104575}

Submitted on 9 Jan 2021

HAL is a multi-disciplinary open access archive for the deposit and dissemination of scientific research documents, whether they are published or not. The documents may come from teaching and research institutions in France or abroad, or from public or private research centers.
L'archive ouverte pluridisciplinaire HAL, est destinée au dépôt et à la diffusion de documents scientifiques de niveau recherche, publiés ou non, émanant des établissements d'enseignement et de recherche français ou étrangers, des laboratoires publics ou privés. 


\title{
Beyond Imperviousness: The Role of Antecedent Wetness in Runoff Generation in Urbanized Catchments
}

\author{
Mohamed Saadi*, Ludovic Oudin, Pierre Ribstein \\ Sorbonne Université, CNRS, EPHE, UMR METIS, F-75000, Paris, France. \\ Published in Water Resources Research, doi: 10.1029/2020WR028060. \\ *Corresponding author : mohamed.saadi@sorbonne-universite.fr
}

\begin{abstract}
Explaining the response of catchments with a mix of pervious and impervious surfaces requires the inclusion of controls other than catchment imperviousness. In this study, we made use of a large sample of 70,227 events in 852 United States catchments to analyze the interplay of total impervious area (TIA) and antecedent soil moisture $(A S M)$ in determining the event runoff ratio $(R R)$. First, we investigated the importance of $T I A$ as a spatial control compared to other catchment attributes (describing climate and catchment landscape) in explaining the differences between catchments in terms of median eventscale $R R$. Second, we examined the importance of $A S M$ as a temporal control of the variability of $R R$ in comparison with spatial settings and other event characteristics. Third, events were grouped into 30 classes of $T I A$ and 30 classes of $A S M$, and linear regression models were used to analyze the evolution of $R R$ depending on each one of the two independent variables. Results showed the following: (1) Analysis of the importance of space-varying catchment descriptors highlighted the relevance of $T I A$ as a control of catchment response, whereas ASM showed a stronger ability compared to other event characteristics. (2) ASM played a significant role in urbanized catchments as in rural ones. The absence of abrupt changes in the linear model parameters indicates that the impact of urbanization on the relationship between $R R$ and $A S M$ was relatively gradual. (3) Differences in $R R$ between rural and intensively urbanized catchments were observable not only for dry pre-event conditions, but also for wet short-term conditions.
\end{abstract}

\section{Plain language summary}

Urbanization causes a substantial increase in surface sealing which leads to dramatic impacts on water cycle. Reliable projections of the impact of urbanization requires a good understanding of the multiple factors that shape the response of a catchment along a wide range of urbanization levels. In catchments with a mix of urban and natural areas, the interplay of total impervious area $(T I A)$ and antecedent soil moisture $(A S M)$ conditions is still not well elucidated. To fill this gap, we attempted to quantify 
the relative importance of $T I A$ and $A S M$ in determining the event-scale catchment response using a sample of 852 United States catchments. We found that both controls play an important role in runoff generation. Particularly, ASM should be considered even in catchments with a high level of urban cover. We also found that the impact of total impervious area on runoff ratio was relatively gradual, and became significant when TIA exceeded $5 \%$. This study provides a solid empirical understanding of the behavior of urbanized catchments, which is a step toward more reliable prediction of the impact of urbanization on hydrology for urban planning policies.

\section{Introduction}

Runoff is an aggregated result of the interaction of numerous hydrological processes within a catchment. Regarded as the catchment response to climatic forcing, it is a complex function of interrelated factors such as climate, morphology, geopedology, and land use. Hierarchizing these factors is necessary in order to understand and predict the behavior of catchments under change. In particular, urbanization and the associated increase in surface imperviousness constitute perhaps one of the most dramatic human-induced changes with regard to landscapes and hydrological processes (Vörösmarty et al., 2010). Yet, quantifying the impact of urbanization on catchment response is still not straightforward due to balancing factors originating from the non-urbanized part of the catchment as well as the dependency on catchment properties.

The event runoff ratio $(R R)$ is a widely used hydrological metric to characterize the catchment response (Blume, Zehe, and Bronstert, 2007). It expresses the fraction of rainfall that is converted into runoff. Numerous factors drive the variability of $R R$, some of which are variable in time (such as event rainfall depth and intensity, and antecedent soil moisture conditions; see, e.g., Graeff et al., 2012; Hewlett, Fortson, and Cunningham, 1977; Tarasova et al., 2018a), while others reflect the catchment hydrological properties, and thus vary in space from one catchment to another (e.g., climate setting, land use, slope, and soil characteristics; see Addor et al., 2018; Merz and Blöschl, 2009; Tarasova et al., 2018b). In the case of urbanized catchments, $R R$ generally increases with the total impervious area $(T I A)$ of the catchment (Miller and Hess, 2017; Zhou et al., 2017), as a consequence of reduced infiltration due to surface sealing. Although urban-induced imperviousness (measured by $T I A$ ) is widely considered as a major control by many predictive regression relationships in urbanized areas (e.g., Survey, 1994), the effect of urbanization on catchment behavior is dependent on the local physical characteristics (Price, 2011). Hierarchizing all involved factors (i.e., soil, climate, topography, and land use) is thus needed to elucidate the relative importance of each one in influencing the hydrological response, particularly that of TIA.

Antecedent soil moisture ( $A S M$ ) modulates the temporal variability of event-scale $R R$, and thus it is a widely considered control to explain and predict the hydrological behavior of non-urbanized catchments (Berghuijs et al., 2016). Previous studies attempted to represent the interplay of $T$ I $A$ and $A S M$ in the variability of the $R R$ of urbanized catchments (Ando, Musiake, and Takahasi, 1984; Brun and Band, 2000; Zhang and Shuster, 2014), while the relevance of $A S M$ as a control of $R R$ in highly urbanized catchments is still debated. Smith et al. (2013) found that the 5-day antecedent rainfall, used as a proxy for $A S M$, did not play a significant role in the generation of $R R$ for seven urbanized catchments in the Baltimore region (Unites States). Zhou et al. (2017) analyzed the importance of ASM 
for a sample of 16 catchments located in Charlotte, North Carolina, with $T$ I $A$ ranging between 0.08 and 0.50. They found that the influence of $A S M$ on $R R$ decreased with increasing $T I A$. Miller and Hess (2017) analyzed the role of $A S M$ for eight catchments located in the United Kingdom, and found that $R R$ was less dependent on $A S M$ in urbanized catchments than in rural ones.

These studies suggest that $A S M$ plays a less important role in the runoff generation as the catchment imperviousness increases. However, they focused on a small number of catchments, with a range of imperviousness that was not rich enough to reach a general conclusion, nor to quantify the explanatory power of $A S M$ in comparison with TIA.

To address these gaps, we propose to analyze the relationship between the catchment response, materialized by $R R$, and $A S M$ across a wide range of $T I A$. The novelty of this study is the use of a large sample of 70,227 rainfall-runoff events from 852 urbanized and rural catchments located in the United States (US), which offers a large diversity of urbanization levels resulting in a wide range of $T I A$. Another key novelty consists in considering both the space-varying factors (defined as catchment attributes, which vary in space from one catchment to another) and the time-varying factors (defined as factors that vary from one event to another, i.e., event rainfall characteristics and $A S M$ ) by analyzing their relative importance in explaining the spatiotemporal variability of $R R$ along a continuum of catchment imperviousness.

This paper is structured as follows. In Section 2, we present the catchment sample, and we describe how $R R, T I A$, and $A S M$ were estimated. We explain how we assessed the importance of $T I A$ (as a space-varying control) and $A S M$ (as a time-varying control) in predicting $R R$. Then, we detail how the variability of $R R$ was analyzed with regard to $A S M$ and $T I A$, as well as how the sensitivity of $R R$ to each variable was assessed. The results are presented and discussed in Sections 3 and 4, and Section 5 concludes with the main findings and some perspectives.

\section{Dataset and methods}

\subsection{Catchment sample and spatial characteristics}

We used a sample of 852 catchments located in the United States (Saadi, Oudin, and Ribstein, 2019), for which the snow effect and the influence of artificial reservoirs were limited. Their sizes ranged between $1.1 \mathrm{~km}^{2}$ and 21,300 km², with a median value of $321 \mathrm{~km}^{2}$ (interquartile range: $90 \mathrm{~km}^{2}-926 \mathrm{~km}^{2}$ ). The majority of these catchments are located in Southeastern United States, and are characterized by a temperate humid subtropical climate (Beck et al., 2018). Their aridity indices varied between 0.48 and 3.4, and a non-negligible number of catchments are located in areas with relatively high aridity indices (Figure 1), indicating the richness of the catchment sample with regard to climatic settings.

The hourly mean areal precipitation depths were extracted from the National Centers for Environmental Prediction's Stage-IV dataset using the geokn i fe R package (Read et al., 2015; Lin and Mitchell, 2005). This dataset was constructed by mosaicking regional multi-sensor (i.e., radar and gages) precipitation analyses into a national product, gridded over the United States at a $4-\mathrm{km}$ resolution. Hourly mean streamflow data were prepared by processing the instantaneous streamflow measurements, which we extracted from the GAGES-II database maintained by the United States Geological Survey (Falcone, 2011) using the dataRetrieval R package (Cicco et al., 2018). Daily temperature was extracted 

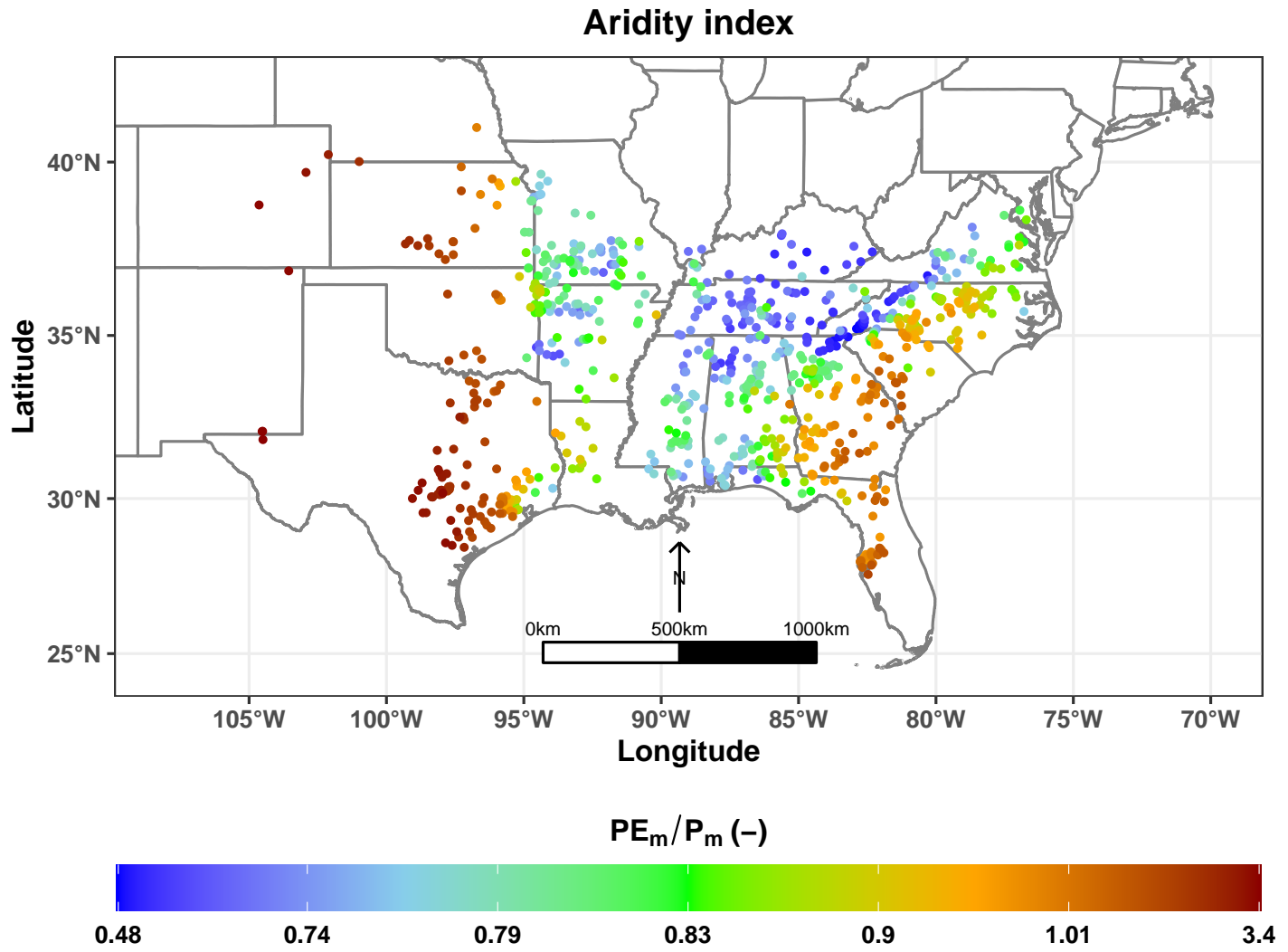

Figure 1. Location and aridity index of the 852 US catchments. Dots represent catchment centroids. Colors indicate aridity indices, computed as the ratio of average annual potential evapotranspiration $P E_{m}$ (mm/year) to average annual precipitation $P_{m}$ (mm/year). 
from the Daymet product (Thornton et al., 2016), available over the United States at a 1-km resolution. Recorded periods span between 2002 and 2017, with lengths ranging from 8 to 16 years.

Landscape and climate settings of each catchment were characterized using an initial set of 23 descriptors (Table 1). The land cover characteristics were extracted from the Multi-Resolution Land Characteristics Consortium's NLCD database, available for the years 2001, 2006, 2011, and 2016 (e.g., Homer et al., 2015) at a 30-m resolution. These included the mean TI A (computed as the arithmetic mean of percentages of sealed surfaces estimated at each catchment pixel), catchment percent developed ( $C P D$, computed as the proportion of catchment area occupied by urbanization classes), the fraction of catchment area with an imperviousness value higher than 0.8 (IMP80), the fraction of forest $(f F O R)$, and the fraction of open water $(f W)$. The distribution of imperviousness values of the catchment was characterized using the irregularity of imperviousness ( Ir IMP). A linear interpolation was used to estimate these characteristics for missing years.

Climate conditions were described using six metrics, including long-term mean precipitation $\left(P_{m}\right)$, flashiness of precipitation $(F P)$, hourly precipitation intensity coefficient $\left(P_{99} / P_{m}\right)$, long-term mean potential evapotranspiration $\left(P E_{m}\right)$, flashiness of potential evapotranspiration $(F P E)$, and aridity index $(A I)$. In addition to the catchment area (Area), the drainage density $(D D)$, the catchment mean slope (Slope), the mean elevation (Elev $v_{m}$ ), and the median value of compound topographic index (CTI) of catchment pixels were chosen to characterize the morphological settings. The mean content of sand (Sand), gravel (Gravel), silt (Silt), and clay (Clay), the mean soil porosity (Porosity) and the mean intrinsic permeability (Perm) were used as geopedological characteristics. Table 1 summarizes the catchment characteristics, their estimation methods, and their corresponding sources. 


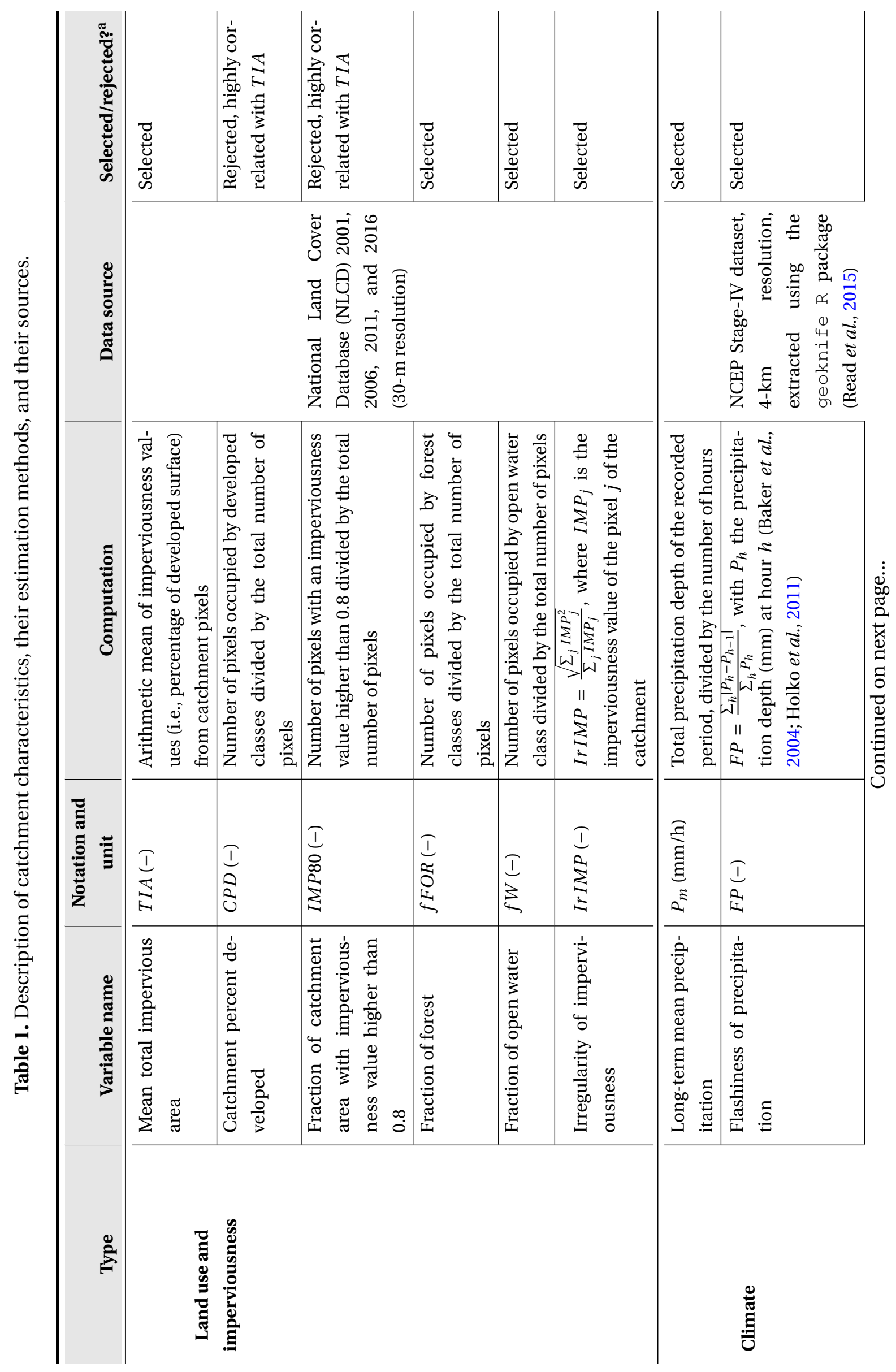




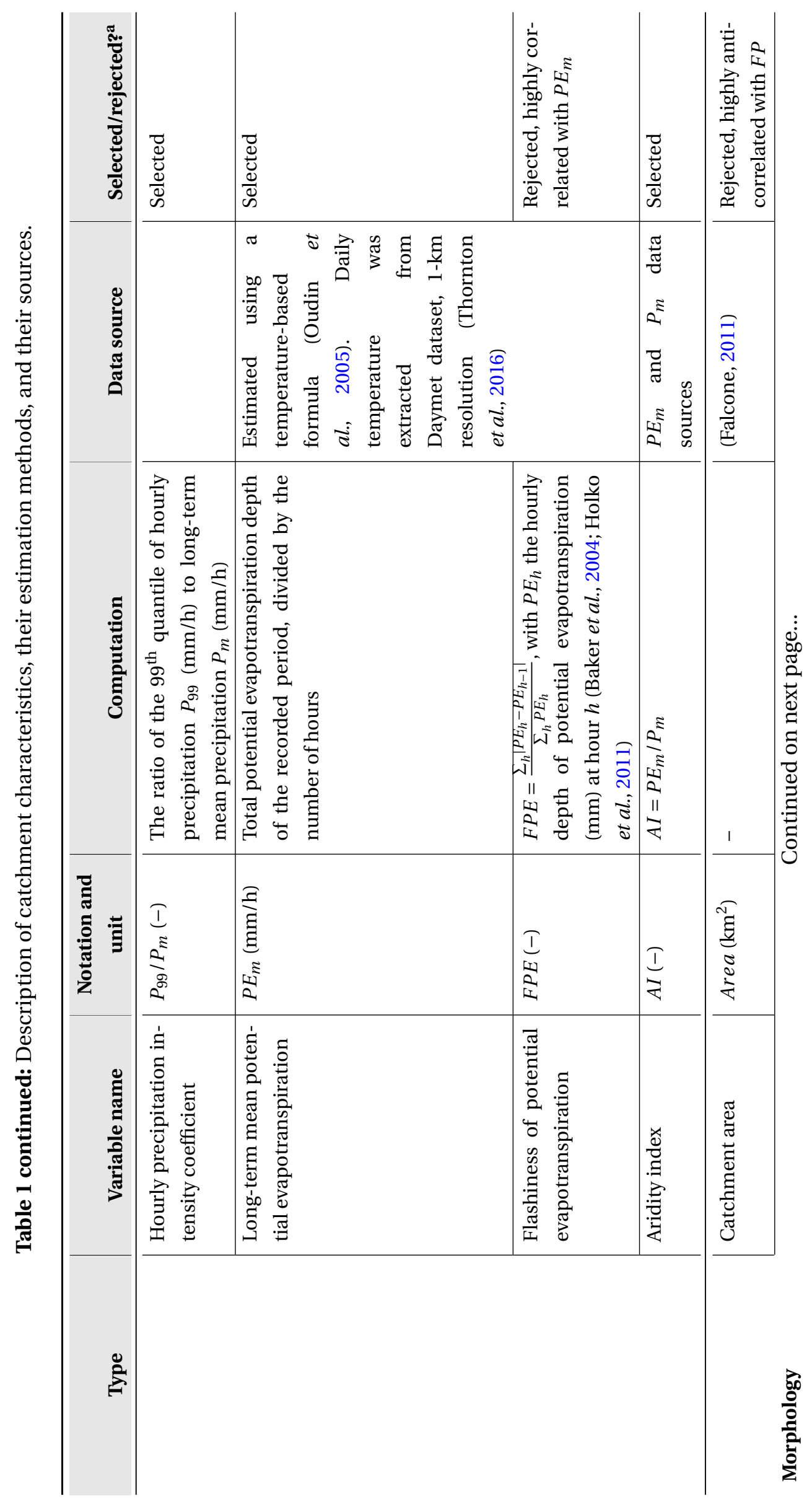




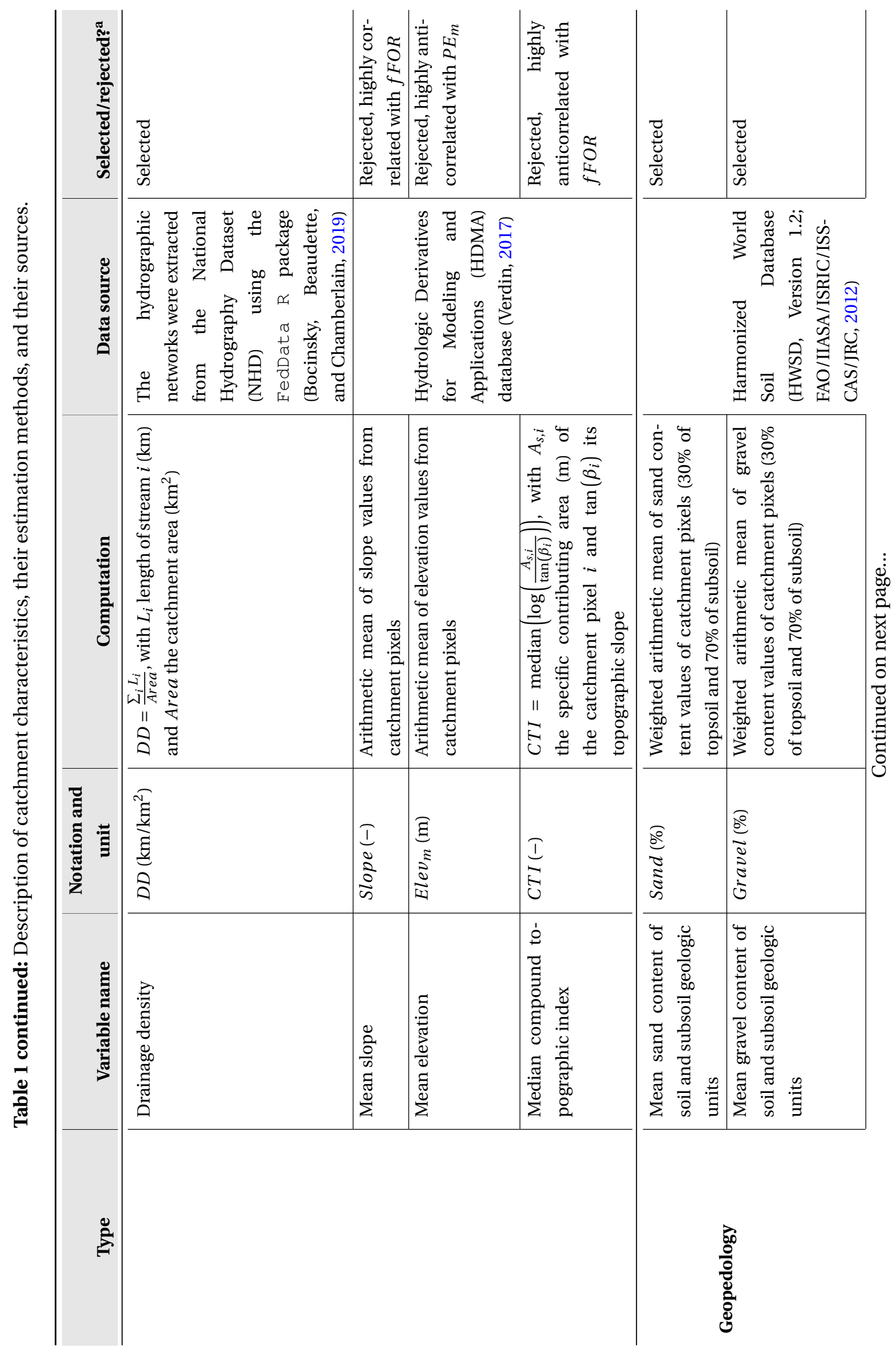




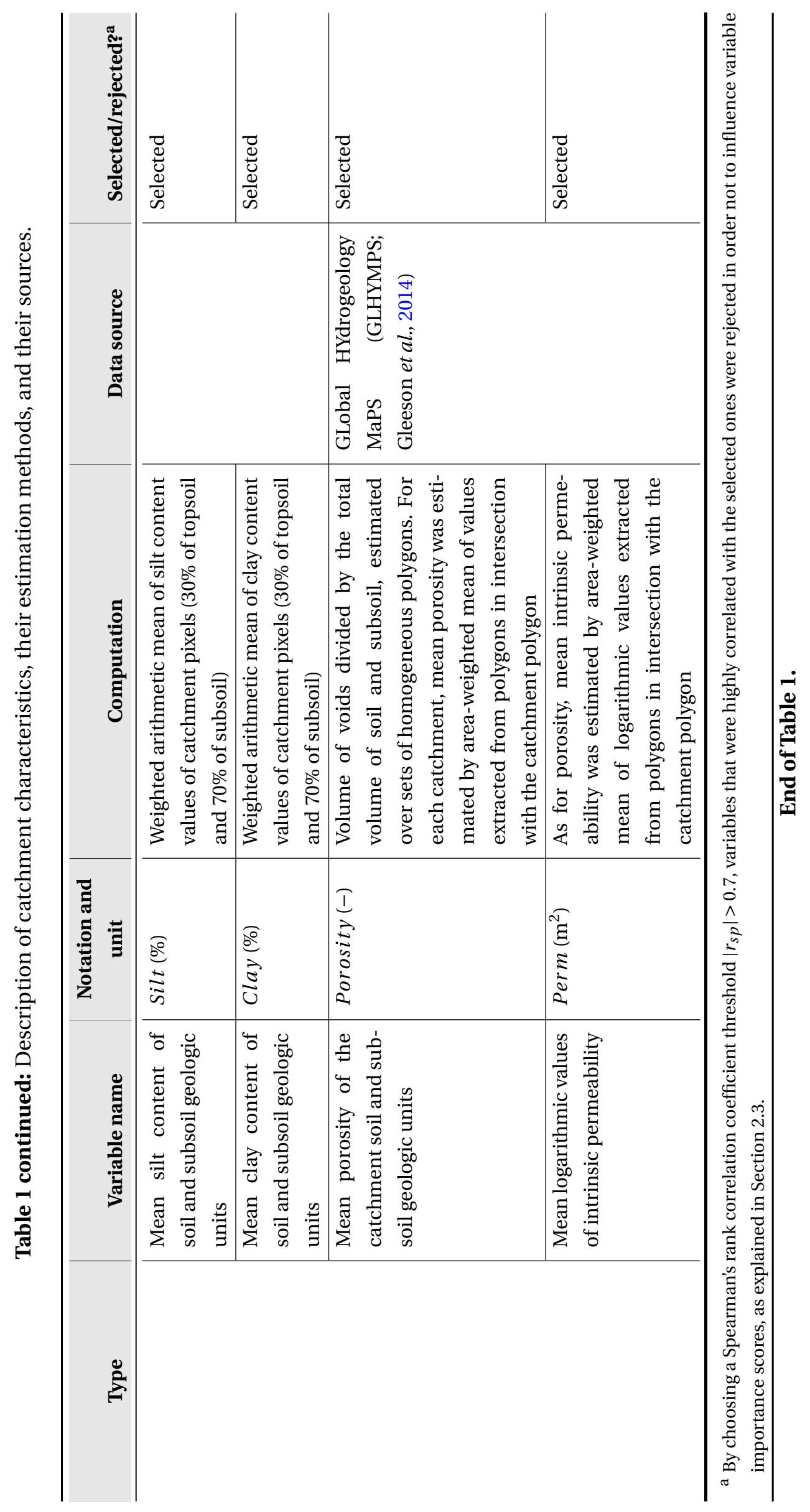




\subsection{Time-varying event and catchment characteristics}

Many event-separation algorithms are reported in the literature (Mei and Anagnostou, 2015; Merz and Blöschl, 2009; Norbiato et al., 2009). The event-separation method used in this paper is detailed in Appendix A, only the three main steps are mentioned hereafter. First, we proceeded by separating the baseflow from the direct flow, using a combination of the constant- $k$ method (Blume, Zehe, and Bronstert, 2007) and a recursive digital filtering algorithm (Collischonn and Fan, 2013; Eckhardt, 2005; Mei and Anagnostou, 2015). Second, the direct flow time series, which is the difference between the total streamflow and the baseflow, was iteratively screened to look for peak flows in the vicinity of which the start and the end of each event were estimated using direct flow thresholds and a bunch of time characteristics estimated from the cross-correlation of direct flow and rainfall. Third, the event was retained after satisfying additional conditions related to peak flow importance, duration, and total rainfall depth. The event $R R$ was computed as the ratio of direct flow to the total rainfall depth. This event-separation algorithm yielded 70,227 events, and the number of events per catchment ranged between 1 and 615, with a median of 50 events per catchment (interquartile range: 23-104).

For each event, a set of time-varying characteristics summarized in Table 2 were estimated. The first group of characteristics is composed of event rainfall depth $P_{\text {tot }}(\mathrm{mm})$, rainfall intensity $P_{\text {int }}(\mathrm{mm} / \mathrm{h})$, and maximum hourly rainfall depth of the event $P_{\max }(\mathrm{mm} / \mathrm{h})$. The second group is a set of variables derived to estimate catchment $A S M$. To this end, four types of proxies were tested:

- The discharge at the start of the event can be considered to reflect the state of catchment moisture (Cappus, 1960; Kirchner, 2009; Tarasova et al., 2018a). Two measures were considered: the total discharge and the baseflow at the start of the event, both normalized by the mean annual streamflow of the catchment.

- The commonly applied Natural Resources Conservation Service's Curve Number (NRCS-CN) method traditionally considers the antecedent precipitation $(A P)$ as a proxy of $A S M$, namely 5day AP (Isik et al., 2013; Soulis et al., 2009). For each event, we have estimated a set of AP measures corresponding to different lengths of time windows before the start of the event, including 2, 5, 10,15 , and 20 days, in addition to a specific period Lag (in hours) estimated for each catchment as the delay $\Delta t$ (in hours) that maximized the correlation between the precipitation time series $P(t)$ and direct flow $Q_{d}(t+\Delta t)$ (see Appendix A).

- The antecedent precipitations index ( $A P I$ ) has been widely used as a proxy of $A S M$ (Berthet et al., 2009; Heggen, 2001; Kohler and Linsley, 1951). It is computed as a weighted sum of the antecedent rainfall depths according to their antecedence in time. As with $A P$, we considered six APIs including 2, 5, 10, 15, and 20 days as well as Lag hours of antecedent precipitation. The weighting parameter was estimated corresponding to a $10 \%$ weight for the earliest considered depth in each API (e.g., the $120^{\text {th }}$ and the $360^{\text {th }}$ hour before the start of each event for 5-day API and 15-day $A P I$, respectively).

- Measures based on soil moisture accounting reservoirs (SMAR; Berthet et al., 2009; Merz, Blöschl, and Parajka, 2006). We used the SMAR of the hourly hydrological model GR4H (Ficchì, Perrin, and Andréassian, 2019), due to its ability to represent $A S M$ as shown in previous studies (Anctil et al., 2004; Javelle et al., 2010). It enables us to make full use of the precipitation $(P)$ and potential 
evapotranspiration $(P E)$ hourly time series to get information on the current hydric state of the catchment. The equations of the $S M A R$ are detailed in Appendix B. The pre-event catchment $A S M$ is taken as the ratio $\frac{S}{S_{\max }}$ at the start of the event, where $S$ is the updated $S M A R$ state $(\mathrm{mm})$ and $S_{\text {max }}(\mathrm{mm})$ the maximum capacity. This ratio varies between 0 (extremely dry condition, i.e., the $S M A R$ is empty) and 1 (extremely wet condition, i.e., the $S M A R$ is full). $S_{\text {max }}$ regulates the $S M A R$ dynamics and memory; setting $S_{\max }$ low allows us to target the short-term wetness conditions (i.e., a few days before the event), whereas large values of $S_{\max }$ make it possible to target wetness conditions on longer terms. Four values of $S_{\max }$ were tested in this study: 10, 50, 100 , and $200 \mathrm{~mm}$. 


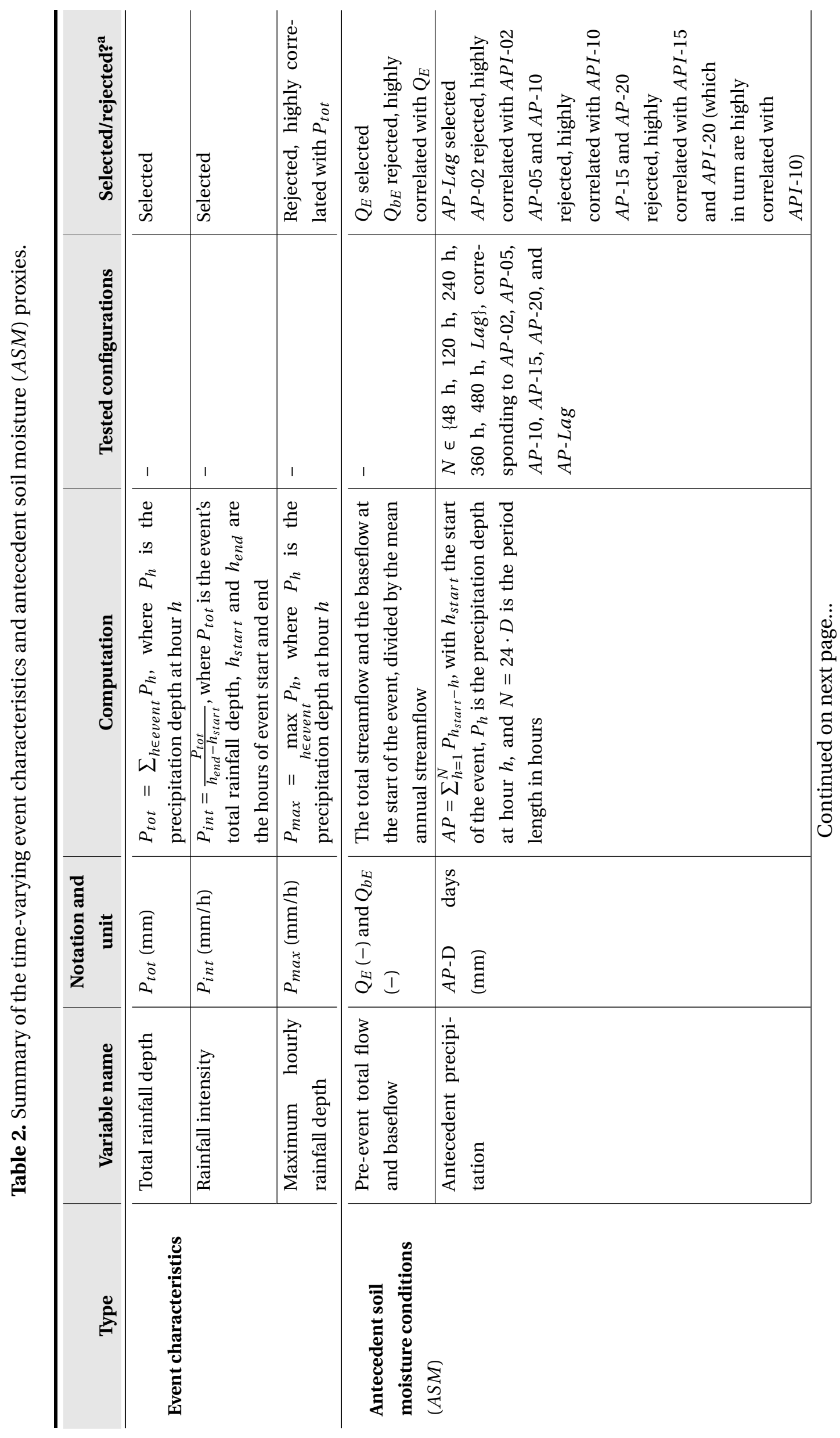




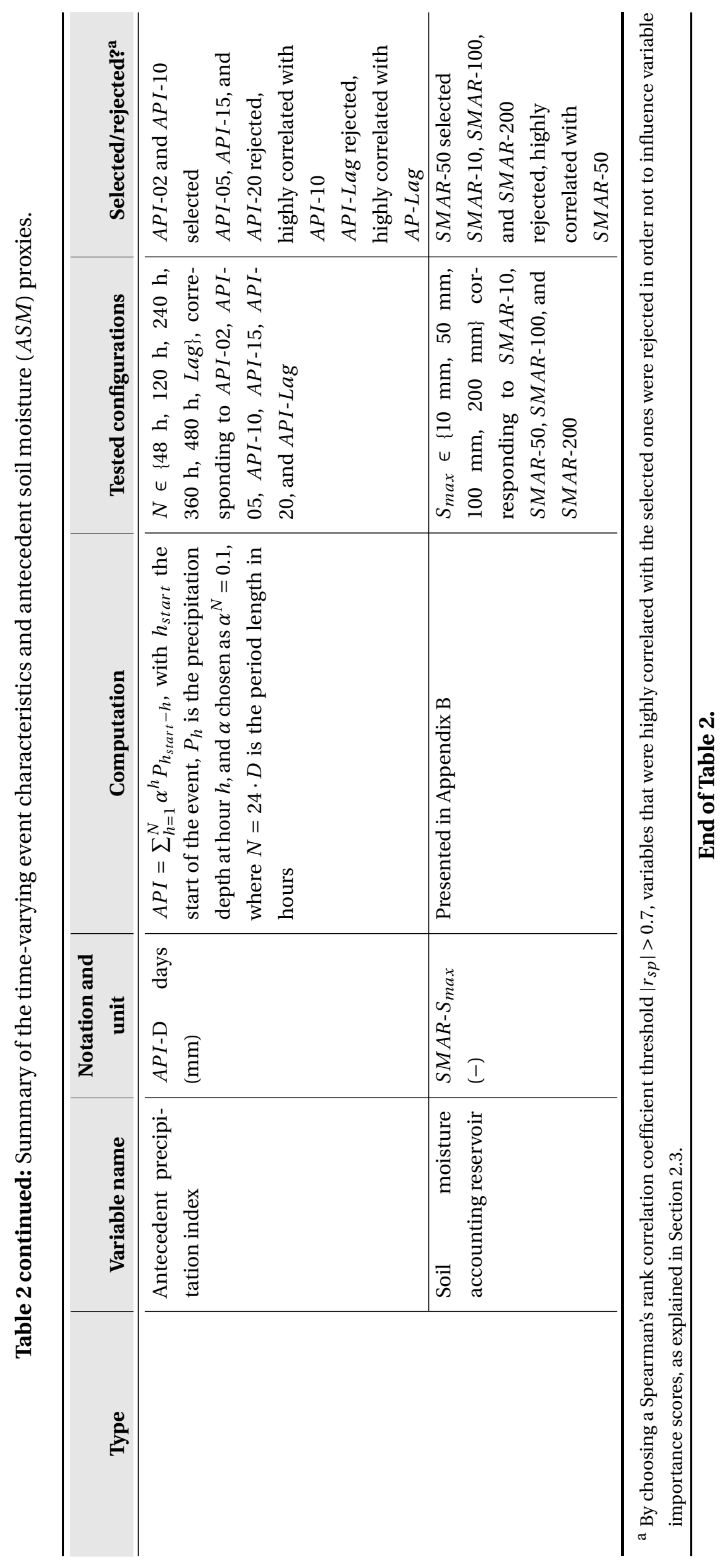




\subsection{Relevance of catchment imperviousness and ASM as controls of the spatial and temporal variability of $R R$}

Before investigating the interplay of catchment imperviousness and ASM in determining event $R R$, we questioned their relevance in comparison with the remaining catchment and event characteristics. First, we ranked the space-varying factors (Table 1) based on their importance as explanatory variables of the evolution of median $R R$ from one catchment to another. This will help to unveil the importance of catchment imperviousness in controlling average catchment hydrological behavior. Second, the timevarying factors (Table 2) were ranked based on their importance in predicting event $R R$, which helped to reveal the variables that mostly contributed to event-to-event variability of catchment response among spatial settings, event rainfall characteristics, and ASM proxies.

In our case, variable ranking was a difficult task as all space-varying and time-varying factors simultaneously and nonlinearly interact to decide the event-scale $R R$. To deal with the nonlinear and multidimensional aspects of the problem, we have employed the random forest algorithm (Breiman, 2001), which has been applied by recent studies that exploited large samples of catchments characterized by a relatively large number of descriptors (Addor et al., 2018; Zhang et al., 2018). In addition, random forest reduces the risk of overfitting and robustly handles nonlinear relationships between predictors while allowing for variable importance assessment. These advantages are achieved thanks to a column and row subsampling strategy. A random forest is constructed by growing a number of regression trees. At each tree growing, a number of independent variables is randomly sampled at each split (generally one third of variables), while a subset of data is left out of the training sample ( $36.8 \%$ of cases) in order to assess the accuracy of the constructed random forest, called out-of-bag (OOB) data. OOB data is used to assess the importance of each variable by randomly shuffling the values of the OOB cases specific to each tree. This random shuffling would lead to a decrease in the accuracy of the constructed random forest, and the greater the decrease in accuracy, the more important the variable in question. The decreases in accuracy are averaged over all the trees that included the considered variable, and the obtained mean is normalized by the standard deviation of decreases to compute the variable's Z-score of importance. As an accuracy measure, the mean squared error $(M S E)$ is utilized, and the most important variables are the ones with the highest increases in MSE.

Using this method, simply ranking variables does not allow for deciding which ones are significantly important. To accomplish this, we used the Boruta algorithm (Kursa and Rudnicki, 2010) implemented in the Boruta R package (Kursa and Rudnicki, 2020). This algorithm creates copies of all variables, called "shadow variables", by shuffling the values of each one of the original variables. Then, both original and shadow variables are combined to run the random forest algorithm implemented in the randomForest R package (Liaw and Wiener, 2002) and obtain variable importance scores. The maximum Z-score of the shadow variables $M Z S V$ is used to assess whether a variable is statistically relevant or not. A variable obtaining a Z-score higher than $M Z S V$ scores a hit. At each iteration, the ratio of the cumulative number of hits to the total number of trials is used to assess the statistical significance of the variable importance by means of a binomial test. The outcome of this statistical test decides whether the variable is significantly relevant, significantly irrelevant, or without decision.

Boruta algorithm was used to rank both the space-varying and the time-varying variables, and decide whether a variable was significantly relevant or irrelevant in predicting $R R$ ( $p$-value $<0.01$ ). As variable ranking is influenced by the multicollinearity of variables, we identified the ones that showed high 
Spearman's rank correlation coefficient (i.e., $\left|r_{s p}\right|>0.7$ ). Among the space-varying descriptors, we selected the ones that were best correlated (in the sense of Pearson's correlation coefficient) with the 852 median event-scale $R R$ per catchment. This has led to a final selection of 16 out of the initial 23 space-varying descriptors, as detailed in Table 1. Similarly, we selected only the time-varying variables that were not highly correlated (Table 2) by preferring the ones that had the best Pearson's correlation with the 70,227 event $R R$ s. This has led to a rejection of 14 initially considered variables, as detailed in Table 2.

Once the 16 space-varying variables were ranked, the ones that were considered to be relevant by the Boruta algorithm were used to predict the median event-scale $R R$ for each catchment. This predicted median $R R$, noted Spatial $R R$, was combined with the 7 selected time-varying variables (Table 2) to rank them based on their importance in predicting the 70,227 event $R R$ s. This helped to compare the importance of $A S M$ variables with that of event rainfall characteristics and catchment descriptors reflected by Spatial $R R$.

\subsection{Investigation of the relationship between RR and ASM for different levels of catchment imperviousness}

In this section, we present the method used to analyze the relationship between $R R$ and two $a$ priori driving characteristics: a time-varying characteristic representing catchment wetness $(A S M)$ and a space-varying characteristic representing the catchment imperviousness (TIA). The 70,227 rainfallrunoff events are grouped into $N_{T I A} \cdot N_{A S M}$ classes, where $N_{T I A}$ is the number of classes of $T I A$ and $N_{A S M}$ the number of classes of the $A S M$ variable (Table 2). For each independent variable ( $T I A$ or $A S M)$, the classes were delimited by variable quantiles $\left(N_{T I A}+1\right.$ quantiles for $T I A$, and $N_{A S M}+1$ quantiles for $A S M$ ) extracted from the event dataset. This pre-clustering aims at: (i) facilitating the visualization of the $R R$ evolution across $T I A$ and $A S M$ classes, and (ii) deriving robust regression models by filtering $R R$ variability among a given class of $T I A$ and $A S M$.

First, the matrix

$$
M R R=\left(\begin{array}{ccc}
M R R_{1,1} & \ldots & M R R_{1, N_{A S M}} \\
\ldots & M R R_{i, j} & \ldots \\
M R R_{N_{T I A}, 1} & \ldots & M R R_{N_{T I A}, N_{A S M}}
\end{array}\right)_{\substack{1 \leq i \leq N_{T I A} \\
1 \leq j \leq N_{A S M}}}
$$

is constructed, where $M R R_{i, j}$ represents the mean of runoff ratios $R R$ for the class $\{i, j\}$ of events for which TIA values are located between the $i^{t h}$ and $(i+1)^{t h}$ quantile of TIA (the $\left(N_{T I A}+1\right)^{t h}$ quantile being the max of $T I A$ of all events) and $A S M$ values are located between the $j^{\text {th }}$ and $(j+1)^{t h}$ quantile of $A S M$ (the $\left(N_{A S M}+1\right)^{\text {th }}$ quantile being the max of $A S M$ of all events), with $1 \leq i \leq N_{T I A}$ and $1 \leq j \leq N_{A S M}$. This matrix is constructed to qualitatively understand how $R R$ varies along the $T I A$ axis (i.e., urbanization-induced contrasts) and $A S M$ axis (i.e., wetness state-induced contrasts). In particular, $M R R_{1,1}$ and $M R R_{N_{T I A}, 1}$ represent the mean $R R$ under dry conditions for the least and highest urbanized cases, respectively, whereas $M R R_{1, N_{A S M}}$ and $M R R_{N_{T I A}, N_{A S M}}$ represent the mean $R R$ under wet conditions for the least and highest urbanized cases, respectively.

Second, in order to quantify the $R R$ gradient along $T I A$ and $A S M$ axes, a weighted least squares 
(WLS) regression model was fitted to each row (i.e., $R R$ as a linear function of $A S M$ for a given class of urbanization) and each column (i.e., $R R$ as a linear function of $T I A$ for a given class of antecedent wetness conditions). The goodness of fit is estimated using the coefficient of determination $R^{2}$. In particular, the explanatory power of $A S M$ across all the classes of $T I A R^{2}(R R, A S M)$ is computed as:

$$
\left\{\begin{array}{l}
R_{i}^{2}(R R, A S M)=1-\frac{\left.\sum_{j=1}^{N_{A S M}} w_{i, j} \cdot\left(M R R_{i, j}-M R \overline{R_{i, j}(A S M}\right)\right)^{2}}{\sum_{j=1}^{N_{A S M}} w_{i, j} \cdot\left(M R R_{i, j}-\overline{M R R_{i}}\right)^{2}} ; 1 \leq i \leq N_{T I A} \\
R^{2}(R R, A S M)=\operatorname{median}_{1 \leq i \leq N_{T I A}} R_{i}^{2}(R R, A S M)
\end{array}\right.
$$

where $M R R_{i, j}$ is the element $\{i, j\}$ of matrix $M R R$ (Equation 2.1), $\left.\left\{M R \overline{R R_{i, j}(A S} M\right)\right\}_{1 \leq j \leq N_{A S M}}$ are estimations from the regression line $R R=f(A S M)$ for the class $i$ of $T I A$, and $\overline{M R R_{i}}$ is the weighted mean of $\left\{M R R_{i, j}\right\}_{1 \leq j \leq N_{A S M}}$ for the class $i$. The weights $w_{i, j}$ were chosen as the inverse of the variance of $R R$ of each class $\{i, j\}$ to account for the intraclass variability of $R R$. Similarly, the explanatory power of $T I A$ across the $A S M$ classes is estimated as:

$$
\left\{\begin{array}{l}
R_{j}^{2}(R R, T I A)=1-\frac{\left.\sum_{i=1}^{N_{T I A}} w_{i, j} \cdot\left(M R R_{i, j}-M \overline{R R_{i, j}(T I} A\right)\right)^{2}}{\sum_{i=1}^{N_{T I A}} w_{i, j} \cdot\left(M R R_{i, j}-\overline{M R R_{j}}\right)^{2}} ; 1 \leq j \leq N_{A S M} \\
R^{2}(R R, T I A)=\operatorname{median}_{1 \leq j \leq N_{A S M}} R_{j}^{2}(R R, T I A)
\end{array}\right.
$$

where $\left.\left\{M \widehat{R R_{i, j}(T I} I A\right)\right\}_{1 \leq i \leq N_{T I A}}$ are estimations from the regression line $R R=f(T I A)$ for the class $j$ of $A S M$, and $\overline{M R R_{j}}$ is the weighted mean of $\left\{M R R_{i, j}\right\}_{1 \leq i \leq N_{T I A}}$ for the class $j$.

Then, we analyzed the evolution of the parameters (i.e., slope and intercept) of the regression line $R R=f(A S M)$ along the $T I A$ classes, as well as the evolution of the parameters of the regression line $R R=f(T I A)$ along the $A S M$ classes.

\section{Results}

\subsection{Assessing the relevance of catchment imperviousness and ASM as explanatory variables of event-scale RR}

The catchment land-use characteristics, namely $T I A$ and fraction of forest ( $f F O R$ ), were the most important variables in explaining the spatial variability of median event $R R$, as indicated by Figure 2a. Aridity index $(A I)$ obtained almost similar importance scores to those of $f F O R$, followed by mean content of gravel ( $\mathrm{Gravel}$ ), coefficient of hourly precipitation intensity $\left(P_{99} / P_{m}\right)$, and mean intrinsic permeability (Per $\mathrm{m}$ ), proving the strong controls of climatic and geopedological conditions over the catchment response. The following group of controls had equivalent importance scores, with mean content of silt (Silt) and flashiness of precipitation ( $F P$ ) slightly ahead of mean content of sand (Sand), clay (Clay), and long-term averages of precipitation and potential evapotranspiration $\left(P_{m}\right.$ and $\left.P E_{m}\right)$. The last group of controls was constituted by the drainage density $(D D)$ and the remaining land-use characteristics ( $f W$ and $\operatorname{Ir} I M P$ ). Nonetheless, all the variables were confirmed significantly important in explaining the spatial variability of $R R$, illustrating the multi-dependency of $R R$ on catchment attributes. 
Spatial $R R$, the predicted median $R R$ for each one of the 852 catchments by random forest using the space-varying characteristics, proved to be the most relevant feature to explain the spatiotemporal variability of event $R R$, as shown in Figure $2 \mathrm{~b}$. This underlines the importance of the physical properties of the catchment in modulating its event-scale $R R$. The second most important control after Spatial $R R$ was $S M A R-50$, underscoring the high importance of $A S M$ as a primary control of $R R$ ahead of rainfall characteristics, and the usefulness of the $S M A R$ technique as a proxy for $A S M$ in predicting RR. Spatial $R R$ and $S M A R-50$ were followed by the pre-event discharge $\left(Q_{E}\right)$ and event characteristics $\left(P_{i n t}\right.$ and $\left.P_{t o t}\right)$. A final group of time-varying variables was formed by the remaining $A S M$ proxies ( $A P I-02, A P I-10$, and $A P$ - $L a g$ ), suggesting their relatively low relevance in explaining $R R$ compared to other event characteristics. Finally, all employed variables were confirmed to be significantly important.

\subsection{Analyzing RR variability using TIA and SMAR as a surrogate of ASM}

$R R$ is similarly controlled by both the imperviousness level, i.e., TIA, and the short-term ASM, estimated by $S M A R-50$, as shown in Figure 3. In particular, the $R R$ in highly urbanized catchments (i.e., high $T I A$ ) was sensitive to changes in SMAR-50. Mean RR per each class of TIA and SMAR50 varied between 0.01 and 0.43 , the lowest values being attained for the rural cases during the dry period (bottom-left area in Figure 3), whereas the highest values were attained for the most urbanized cases during the wet period (top-right area in Figure 3). Moving from dry to wet conditions, mean $R R$ increased for all catchments regardless of their level of $T$ IA. Similarly, higher values of $T$ IA always resulted in higher values of mean $R R$ for all $A S M$ conditions. Similar patterns were obtained using pre-event discharge measures, $A P$ and $A P I$ metrics instead of $S M A R-50$ (not shown here).

The obtained WLS linear regression models were satisfactory for both $S M A R-50$ and $T I A$, with median $R^{2}(R R, S M A R-50)=0.90$ over the 30 classes of $T I A$ (range: $\left.0.78-0.95\right)$ and $R^{2}(R R, T I A)=0.76$ over the 30 classes of $S M A R-50$ (range: $0.30-0.92$ ). The goodness of fit is illustrated by examples in Figure 4 for the least and most urbanized cases (bottom and top rows of Figure 3 ) and the lowest and highest ASM conditions (left and right columns of Figure 3). The first two examples (Figures $4 \mathrm{a}$ and $4 \mathrm{~b}$ ) illustrate the effect of $S M A R$-50 on mean event $R R$, where an increase in $S M A R$-50 was accompanied by increasing mean $R R$ similarly for both the least urbanized cases and the most urbanized cases. The last two examples (Figures $4 \mathrm{c}$ and $4 \mathrm{~d}$ ) indicate the effect of $T I A$ on mean event $R R$, where $R R$ got increased with increased $T I A$. The effect of $T I A$ is visually more pronounced amid dry conditions (i.e., very low $S M A R-50$ ) than in wet conditions (i.e., very high $S M A R-50$ ), but in both cases the differences in $T I A$ were accompanied by differences in catchment response. 
(a)

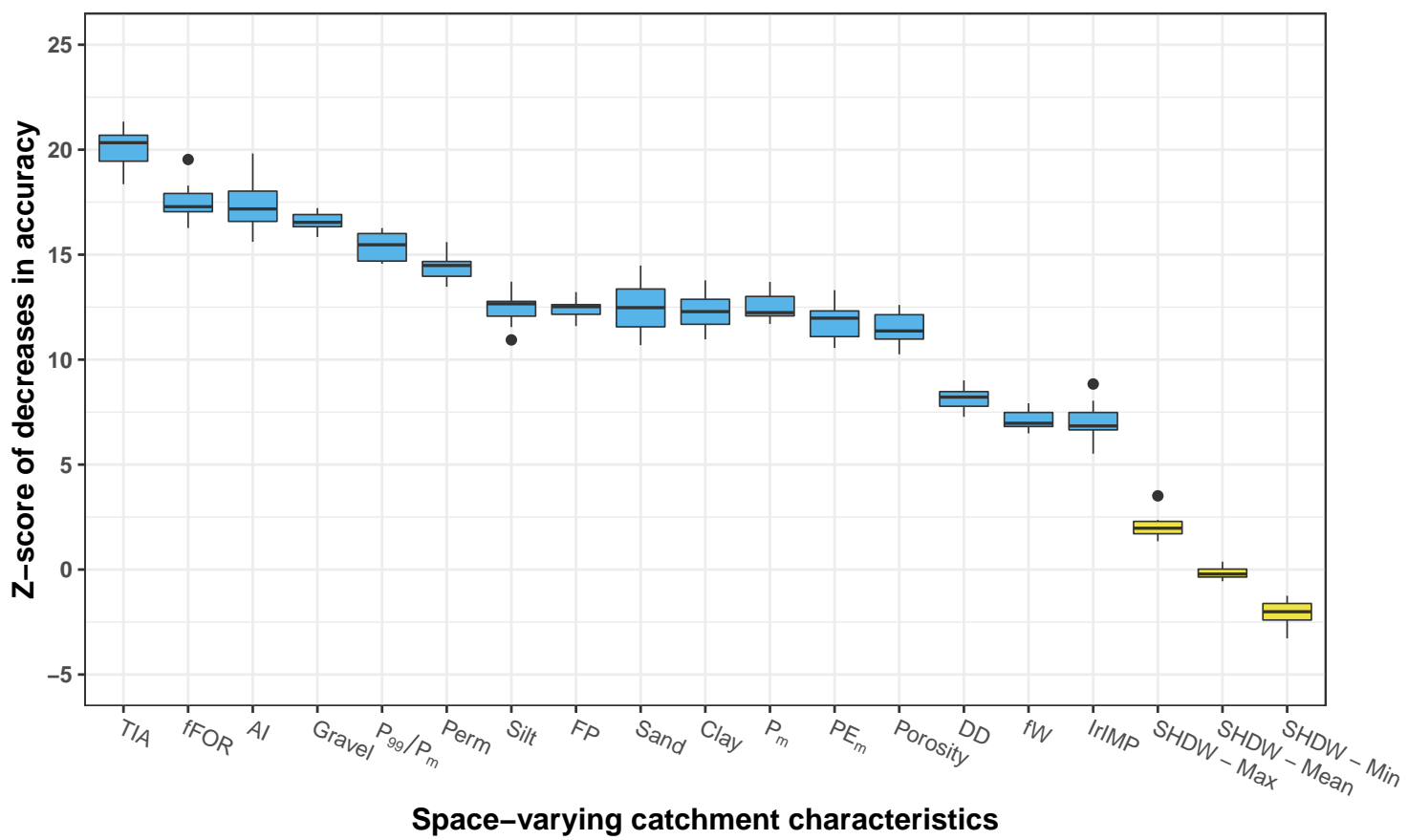

(b)

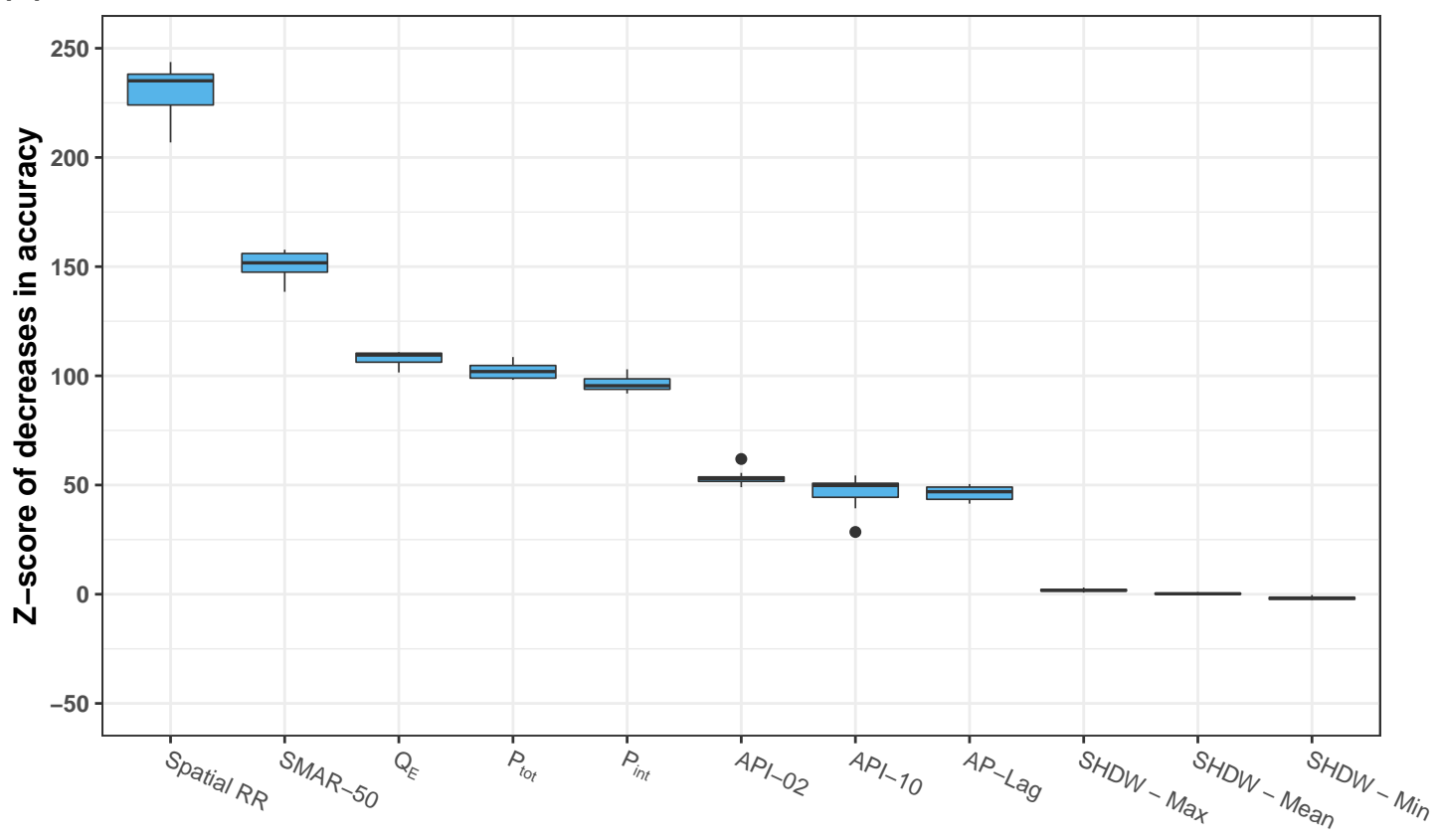

Time-varying event and catchment characteristics

Figure 2. (a) Rankings of space-varying catchment characteristics (Table 1), based on their importance in explaining the variability of the 852 median catchment event-scale runoff ratios, and (b) rankings of Spatial RR and time-varying event and catchment characteristics (Table 2), based on their importance in explaining the variability of the 70,227 event runoff ratios. Importance is estimated using the Z-score of decreases in accuracy, i.e., of increases in mean squared errors (MSE) of the predictions of random forests. Spatial $R R$ is the prediction of median catchment runoff ratio estimated by random forest using the space-varying catchment descriptors. SHDW-Max, SHDW-Mean and SHDW-Min are the distributions of maximum, mean and minimum values of $Z$-score of shadow variables, obtained using the Boruta R package. 

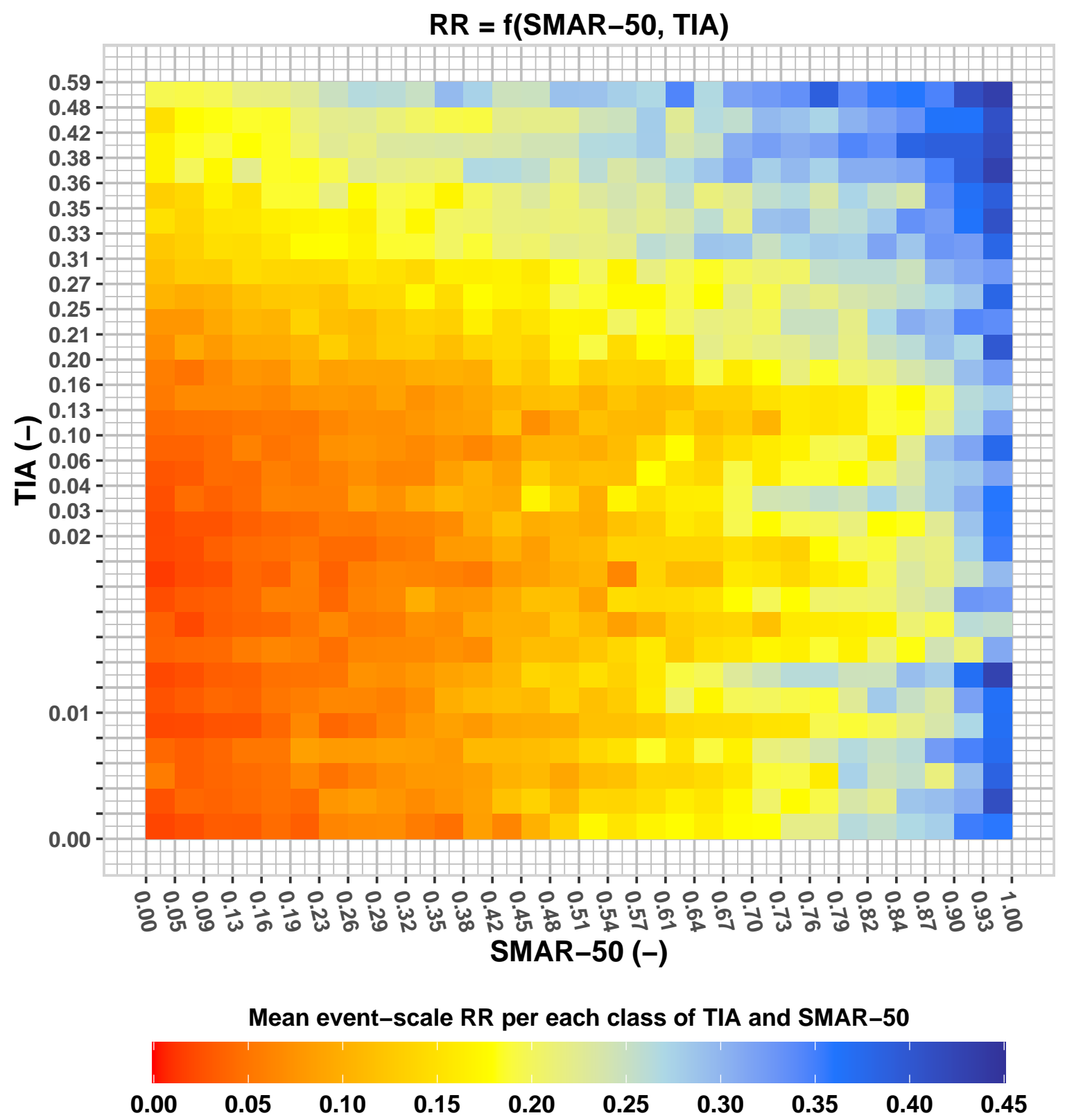

Figure 3. Runoff ratio $(R R)$ dependence on antecedent soil moisture (ASM) conditions, assessed using the level of the soil moisture accounting reservoir (SMAR-50, Appendix B), and the catchment total impervious area (TIA). This matrix was constructed by setting $N_{T I A}=N_{S M A R-50}=30$, yielding 900 classes of $T I A-S M A R-50$. The bottom row shows the evolution of mean $R R$ for rural cases (i.e., $T I A$ close to 0 ), and the top row shows mean $R R$ for intensively urbanized ones (i.e., $T I A$ between 0.48 and 0.59 ). The left column shows mean $R R$ for dry conditions (i.e., $S M A R-50$ close to 0 ), and the right column shows mean $R R$ for wet conditions (i.e., SMAR-50 close to 1$)$. 
Mean event RR function of SMAR-50 for the lowest and highest urbanized cases

(a)

$R R=f(S M A R-50)$ for $T I A \in[0,0.002]$

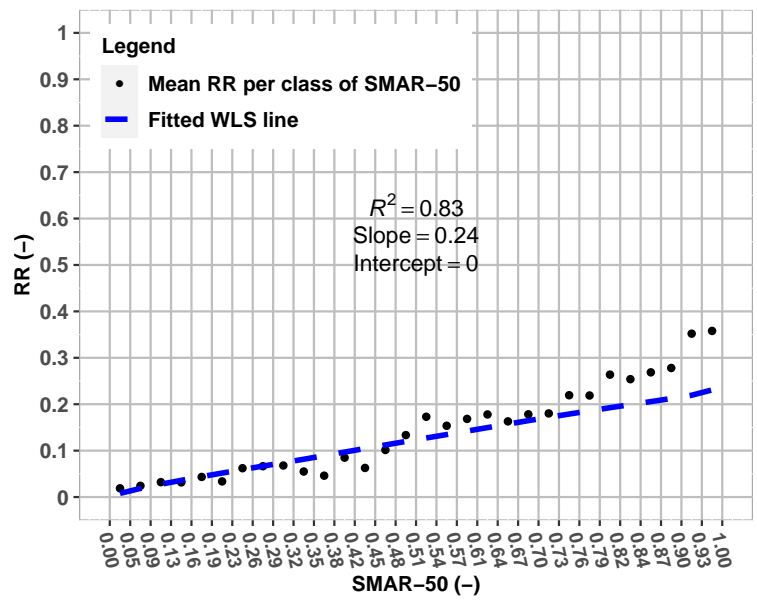

(b)

$R R=f(S M A R-50)$ for $T I A \in[0.48,0.59]$

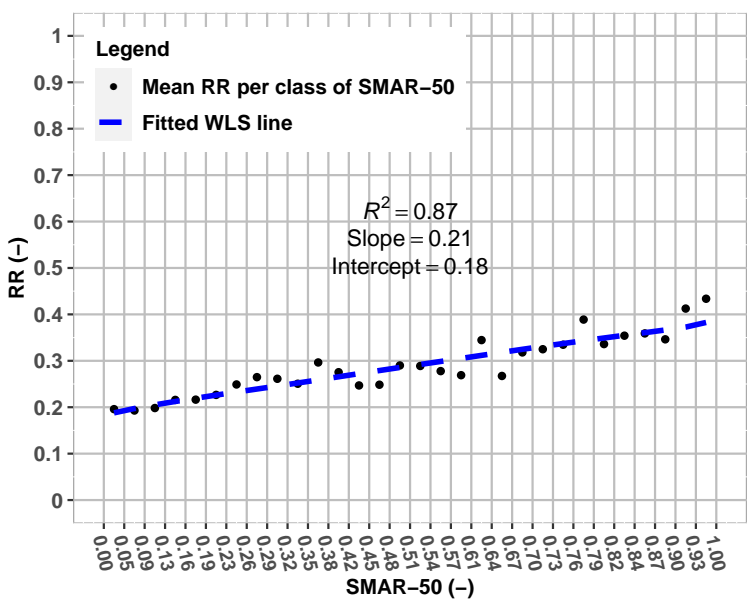

(c)

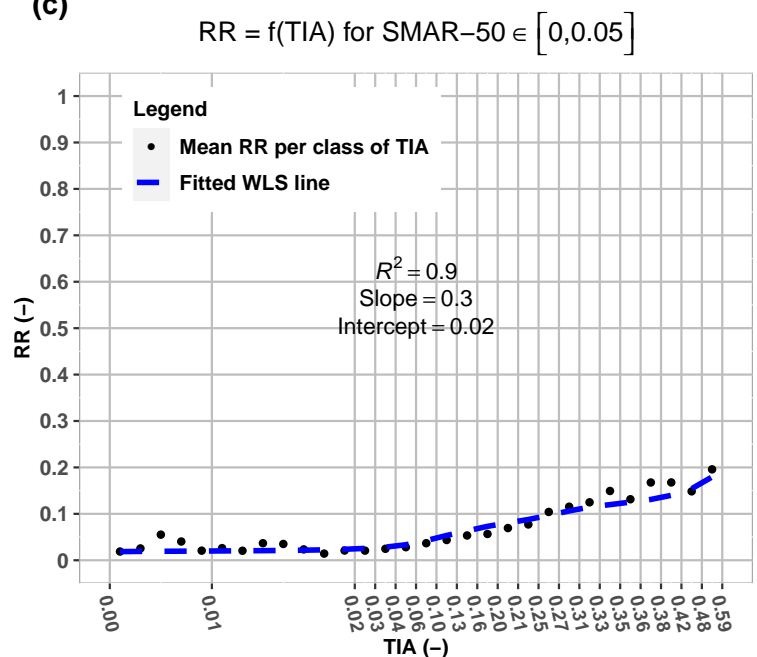

(d)

(d) $R R=f(T I A)$ for SMAR-50 $\in[0.93,1]$

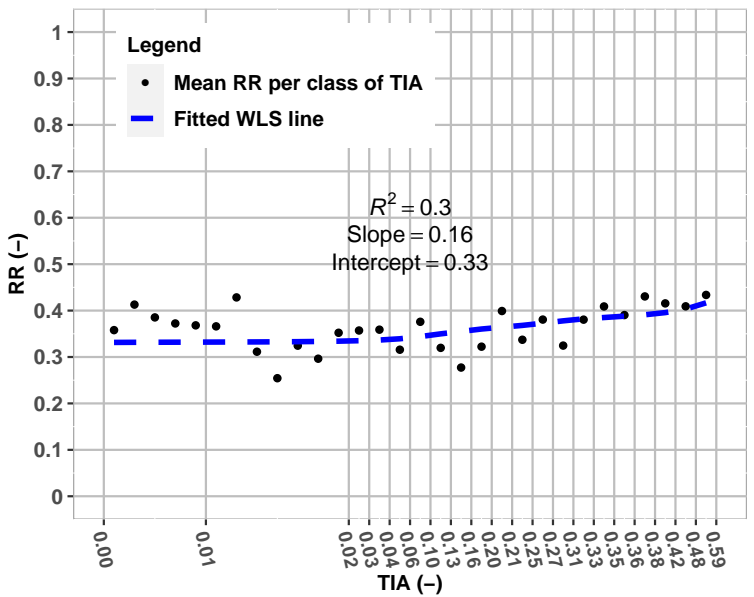

Figure 4. Scatter plots showing the variability of mean runoff ratio $(R R)$ as a function of total impervious area $(T I A)$ and antecedent soil moisture $(A S M)$, assessed using the level of the soil moisture accounting reservoir ( $S M A R-50$, Appendix B). The first row shows $R R=f(S M A R-50)$ for (a) the lowest $T I A$ level and (b) the highest $T I A$ level. The second row shows $R R=f(T I A)$ for (c) the driest $A S M$ conditions and (d) the wettest $A S M$ conditions. Black dots show mean $R R$ per class of $T I A$ and $S M A R-50$, and blue dashed lines show the fitted weighted least squares (WLS) regression models. 
An overview of the evolution of the WLS model parameters suggests that the control of $S M A R-50$ on $R R$ was not influenced by $T I A$, as manifested by the behavior of the slope of the WLS regression line $R R=f(S M A R-50)$ in Figure 5a. In general, the slope did not deviate significantly from 0.21 for all classes of $T$ I A. This means that even for the most urbanized catchments, short-term ASM still played a significant role in determining $R R$ as for the rural ones. The differences between rural and urbanized catchments were most reflected in the intercept parameter, which could be interpreted as the value of $R R$ in very dry conditions (i.e., $S M A R-50$ close to 0 ). The intercept was around zero for catchments with $T I A$ less than $5 \%$, and increased somewhat linearly to reach a value of 0.18 for high levels of $T$ I $A$. This suggests that in dry conditions, $R R$ is solely controlled by the impervious part of the catchment. Varying intercept with almost constant slope is equivalent to shifting upwardly the line $R R=f(S M A R-50)$ as $T I A$ gets higher, as illustrated in Figure 5b.

\section{Discussion}

\subsection{Importance of ASM as a control of RR in urbanized catchments}

This study analyzed the role of $A S M$, in addition to $T I A$, as controls of $R R$. The limited number of studies that have addressed the role of $A S M$ in urbanized catchments suggested that $A S M$ had a less important control on RR compared with TIA (Miller and Hess, 2017; Smith et al., 2013; Zhou et al., 2017). Our results showed that $A S M$ is in fact an important control to consider for predicting the event $R R$ even in catchments with high levels of $T I A$. As reported in some studies (Sillanpää and Koivusalo, 2015; Zhou et al., 2017), the differences between rural and urbanized catchments were essentially during the dry period. We showed that this was also the case for very wet short-term ASM (Figures 3, 4, and 5). Although some of the findings are intuitive, they are purely data-based, and their importance lies most in providing means of revising methods in the practice of hydrology that do not account for the effect of $A S M$ in urbanized areas. In addition, the findings confirm previously obtained results concerning the interplay of $A S M$ and imperviousness, namely the logistic function model proposed by Brun and Band (2000), or the scenario-based conclusions of Zhang and Shuster (2014) and Yang et al. (2011). Methodologically, this study is a stepping stone to overcome the issue of the "rural-urban dichotomy" (McGrane, 2016), by analyzing the evolution of catchment behavior along a continuum of $T I A$, which would not have been possible without the use of a large sample of catchments.

Using $S M A R$ as a proxy for ASM (Appendix B) yielded better predictive power than event characteristics (i.e., $P_{\text {tot }}$ and $P_{\text {int }}$ ) or other $A S M$ proxies that were based on pre-event discharge and antecedent rainfall. The relevance of $S M A R$ as a proxy of $A S M$ has been confirmed in other studies (Anctil et al., 2004; Merz and Blöschl, 2009). Moreover, the $S M A R$ allows us to follow the seasonal variability of $P$ and $P E$, in contrast to $A P I$ that does not distinguish between hot and cold seasons, and the baseflow that is dependent on local configurations other than climate (e.g., soil type, connectivity of surface water and groundwater). The ranking of $A S M$ proxies in this study is very helpful for event-based techniques applied to estimate runoff in urbanized areas. In particular, the NRCS-CN method would be enhanced by using SMAR-50 or API measures in estimating ASM instead of 5-day AP.

The large range of $T I A$ values tested in this study showed that the impact of increasing $T I A$ on the relationship between $R R$ and $A S M$ was more gradual than threshold-like. As illustrated by the evolution 
(a) Parameters of RR $=f(S M A R-50)$ function of TIA

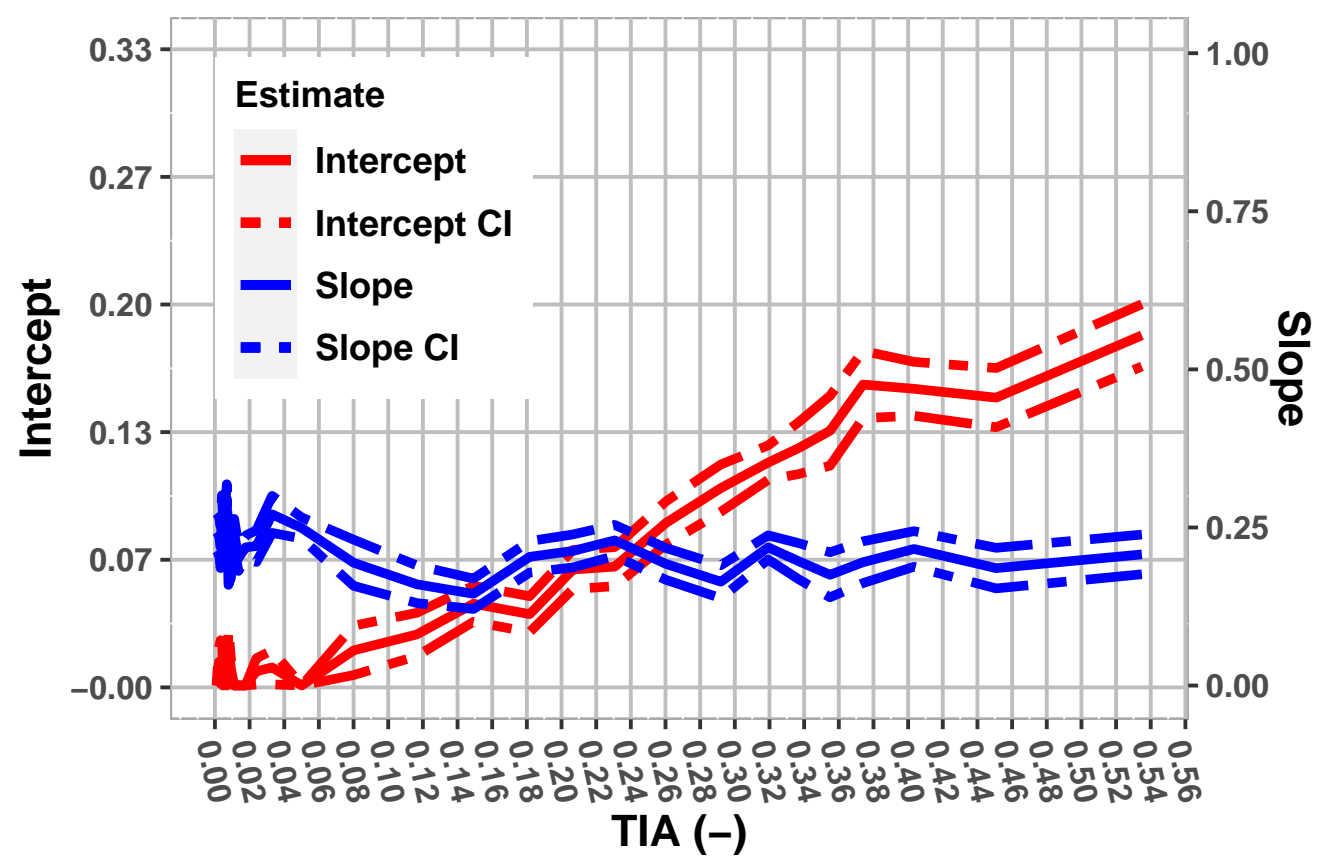

(b) Evolution of $R R=f(S M A R-50)$ for different TIA

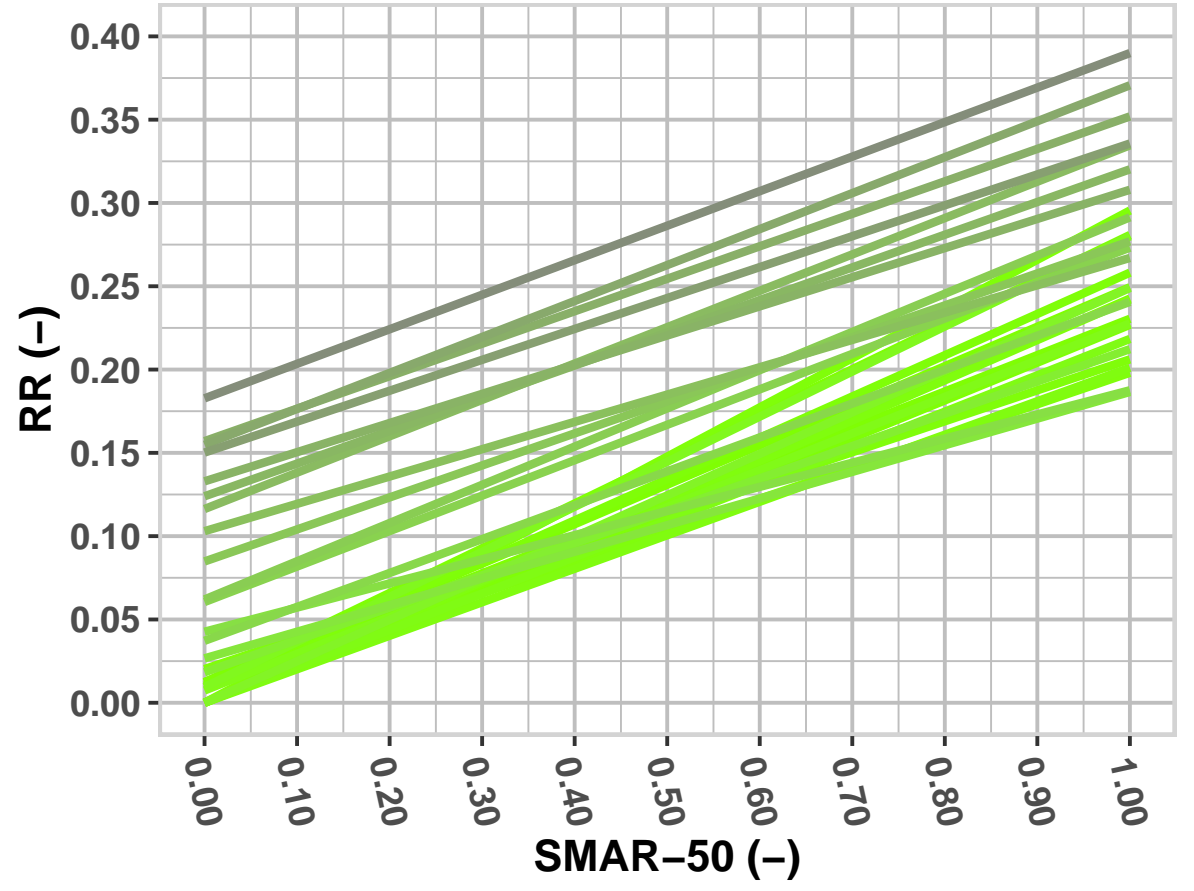

TIA (-)

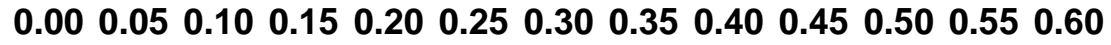

Figure 5. (a) Evolution of the parameters of the WLS regression line representing mean runoff ratio $(R R)$ as a function of $S M A R-50$ for different levels of total impervious area $(T I A)$. Estimates are shown with solid lines, and 95\% confidence intervals (CI) are shown with two-dashed lines. Parameter estimates that were not statistically different from zero ( $p$-value threshold at 0.05 ) were set to zero. (b) Evolution of the corresponding lines for different levels of TIA. 
of the parameters of the regression line representing $R R$ as a function of $S M A R-50$ (Figure $5 \mathrm{a}$ ), for different values of $T I A$, the intercept started to deviate from zero as $T$ I $A$ exceeded 0.05 , but no abrupt change was noticed. This advocates the continuousness of the effect of urbanization (see the discussion in Brabec, Schulte, and Richards, 2002), and implies that it would be difficult to detect a significant change in catchment behavior (in response to urbanization) if the absolute change in TIA or the difference between analyzed situations (as in a paired-catchment framework) is less than $10 \%-5 \%$. The threshold of $T I A$ above which the intercept became significantly different from zero (i.e., 0.05 ) has been reported in literature reviews (Alley and Veenhuis, 1983; Brabec, Schulte, and Richards, 2002; Salvadore, Bronders, and Batelaan, 2015).

Some would argue that $T$ I A did not exceed 0.6 for the sample used here, leaving a relatively large range of $T I A$ uncovered. When examining the proportion of the catchment that is occupied by urbanization classes, i.e., CPD (Falcone, 2011; Miller and Hess, 2017), this proportion varied between $0 \%$ and $100 \%$, with a median value of $29 \%$, meaning that the range of $T$ I $A$ used here covered a large variety of situations of catchment-scale urban sprawl, including catchments completely occupied by urbanization classes. Not reaching a TIA higher than 0.6 is perhaps a result of focusing on the catchment scale, as the minimum catchment size in this study is above $1 \mathrm{~km}^{2}$, which implies the existence of more natural surfaces (i.e., with low imperviousness values) even for intensively urbanized catchments.

\subsection{Relevance of other catchment and event characteristics in explaining the variability of RR}

In addition to TIA, $F F O R$ had the highest importance in explaining the variability of median event $R R$ for the catchment set, highlighting the primary control of land-use characteristics on catchment behavior (Merz and Blöschl, 2009; Tarasova et al., 2018b). Climate characteristics (the aridity index and the coefficient of hourly precipitation intensity $\left.P_{99} / P_{m}\right)$ and geopedological settings were the next most relevant spatial controls, underscoring the interplay of climate and landscape features in defining the catchment long-term hydrological behavior (Gao et al., 2018; Merz and Blöschl, 2009). Comparing the importance of spatial and temporal controls on the variability of event-scale $R R$ illustrated the primacy of regional settings over $A S M$ and event rainfall characteristics (Figure 2b), as the former defines the long-term behavior of the catchment while the latter shapes the short-term high-frequency variability (Merz and Blöschl, 2009). Event rainfall characteristics have been regularly chosen as explanatory variables (Blume, Zehe, and Bronstert, 2007; Hewlett, Fortson, and Cunningham, 1977; Tarasova et al., 2018a), which has been confirmed by our study results (Figure 2b), but their importance was less than that of regional settings and ASM conditions.

Lastly, it has been shown that not only TIA influences catchment response, but also the spatial arrangement of impervious surfaces (Debbage and Shepherd, 2018; Mejía and Moglen, 2010), which has motivated to search for a more hydrologically relevant imperviousness measure, such as the effective impervious area $(E I A)$ or the landscape fragmentation measures (Alley and Veenhuis, 1983; Ebrahimian, Wilson, and Gulliver, 2016; Oudin et al., 2018). Moreover, not all urbanized cover is impervious to water (Berthier, Andrieu, and Creutin, 2004; Ragab et al., 2003; Ramier, Berthier, and Andrieu, 2011; Redfern et al., 2016), and different types of urban cover are characterized by a wide range of imperviousness. In this respect, we used a second-order measure of imperviousness, i.e., Ir IMP, which 
was a relevant indicator but showed a lesser importance compared to the remaining spatial controls in explaining the spatial variability of event-scale $R R$ (Figure 2a).

\section{Conclusion}

In this study, we demonstrated the impact of space-varying and time-varying controls on event $R R$ for a large sample of 852 catchments located in the US, characterized by a wide range of TIA. The main finding was that $A S M$ still plays a significant role in shaping $R R$ even for the most intensively urbanized catchments.

As a spatial control, TIA showed the best ability in explaining the spatial variability of catchment response, ahead of the fraction of forest and the remaining climatic, geopedological, and morphological settings. ASM was estimated by the soil moisture accounting reservoir (SMAR) of the GR4H model, as it was best able to explain the event-to-event variability of $R R$ compared with event characteristics $\left(P_{\text {tot }}\right.$ and $P_{\text {int }}$ ), antecedent precipitation ( $A P$ and $A P I$ ), and pre-event discharge. Still, regional settings had the highest importance in explaining the variability of $R R$ compared to $A S M$ and event rainfall characteristics.

Using the $S M A R$ as a proxy for $A S M$, the events were grouped into 900 classes of $T I A$ and $A S M$. Then, the dependency of $R R$ on $T I A$ and $A S M$ was then quantified by means of linear regression. Mean event-scale $R R$ per each class was found to increase with either increasing TIA or increasing ASM. In the highly urbanized catchments, $R R$ increased as pre-event conditions became wet. Differences in $R R$ were found between rural and intensively urbanized catchments in dry as well as in wet $A S M$ conditions prior to the event. The impact of $T I A$ was less important on the slope of $R R=f(A S M)$, whereas the intercept became significantly different from zero at $T I A>0.05$.

The fact that the TIA was not uniformly distributed led us to adopt a quantile-based clustering procedure, which would have been less harmful given a wider $T I A$ range. Also, more diverse climatic conditions are missing in this study (including hotter and colder climates; see, e.g., Sillanpää and Koivusalo, 2015), which should be included in order to get an overall understanding of the interplay between climate and urbanization. The analysis was restrained here to mean $R R$ values for each class, and an analysis of intraclass variability would help to synthesize the effect of $T$ IA and ASM on the overall distribution of $R R$. For process-based modeling, the findings of this study are highly relevant to better represent/reproduce the rainfall-runoff relationship especially for catchments with evolving urbanization. In addition, they offer means to check the physical soundness of commonly applied regression relationships in practical hydrology in order to enhance the reliability of their predictions.

\section{A Event separation method}

Many event-separation algorithms have been reported in the literature (Mei and Anagnostou, 2015; Merz and Blöschl, 2009; Norbiato et al., 2009; Tarasova et al., 2018a). The method adopted in this work is empirical, and consists of the following steps. 


\section{Step 1: Baseflow separation}

Using numerical filtering-based methods is more practical when working on a large sample of catchments (Tarasova et al., 2018a). We used a combination of the constant- $k$ method (Blume, Zehe, and Bronstert, 2007) and a recursive digital filtering algorithm (Collischonn and Fan, 2013; Mei and Anagnostou, 2015; Eckhardt, 2005). We chose this method for its physical soundness: It hypothesizes that the baseflow is associated with the low-frequency component of the total streamflow. Tarasova et al. (2018a) compared five methods of baseflow extraction, and the method used herein has behaved acceptably.

\section{Step 2: Estimation of characteristic response times}

The direct runoff $Q_{d}$, that is considered to be the catchment response to rainfall events, was computed as the difference between the total flow and the baseflow. To constrain the event selection, we determined a set of catchment characteristic response times based on the cross-correlation of the time series of rainfall and direct flow, besides the direct flow auto-correlation.

Three characteristic response times were determined (Figure 6):

- The lag time Lag (in hours), which is the positive shift $\Delta t$ that maximizes the correction between $Q_{d}(t+\Delta t)$ and $P(t)$.

- Sometimes, the correlogram of $Q_{d}(t+\Delta t)$ and $P(t)$ does not show a sharp maximum and can attain significantly high values for $\Delta t>\operatorname{Lag}$ or $\Delta t<0$. A second metric of response time $\operatorname{Lag}_{\max }$ (in hours) was calculated to account for this issue. The correlogram is scaled by its maximum. Three limits were defined: (1) Limit $_{1}$ corresponded to the peak of the scaled correlogram for $\Delta t<0$; (2) Limi $t_{2}$ was taken as the peak of the scaled correlogram for $\Delta t>d e c$, where $d e c$ corresponded to the moment when the correlogram reincreased for the first time; and (3) an arbitrary limit of $\mathrm{Limit}_{3}=0.2$ (i.e., $20 \%$ of the maximum value of the correlogram). The maximum of these three limits, noted LimitPQd, was then explored in the scaled correlogram, and $L_{a g}$ max was the shift corresponding to this limit.

- The auto-correlogram of $Q_{d}$ was also investigated to determine the memory Mem (in hours) of the catchment. Normally, the auto-correlogram should decrease for any $\Delta t>0$. Mem corresponded to the peak of the auto-correlogram for $\Delta t>d e c_{Q_{d}}$, where $d e c_{Q_{d}}$ is the moment at which the autocorrelogram reincreased for the first time. When no reincrease was registered, $\mathrm{Mem}$ corresponded to the shift at which an autocorrelation of LimitQd $=0.2$ was attained for the first time.

\section{Step 3: Estimation of the start of the event}

The time series of $Q_{d}(t)$ were screened to look for a peak flow $Q_{d}^{p}$. Once found, a limit $Q_{d}^{\text {start }}$ function of $Q_{d}^{p}$ was determined. Over a time window $T W_{\text {start }}$, the first estimation of the start of the event corresponds to the moment when $Q_{d}(t)=Q_{d}^{\text {start }}$. The rainfall depth over a time window $T W P_{\text {start }}$ before the start should be less than $10 \%$ of the rainfall depth between the start and the peak moments. 

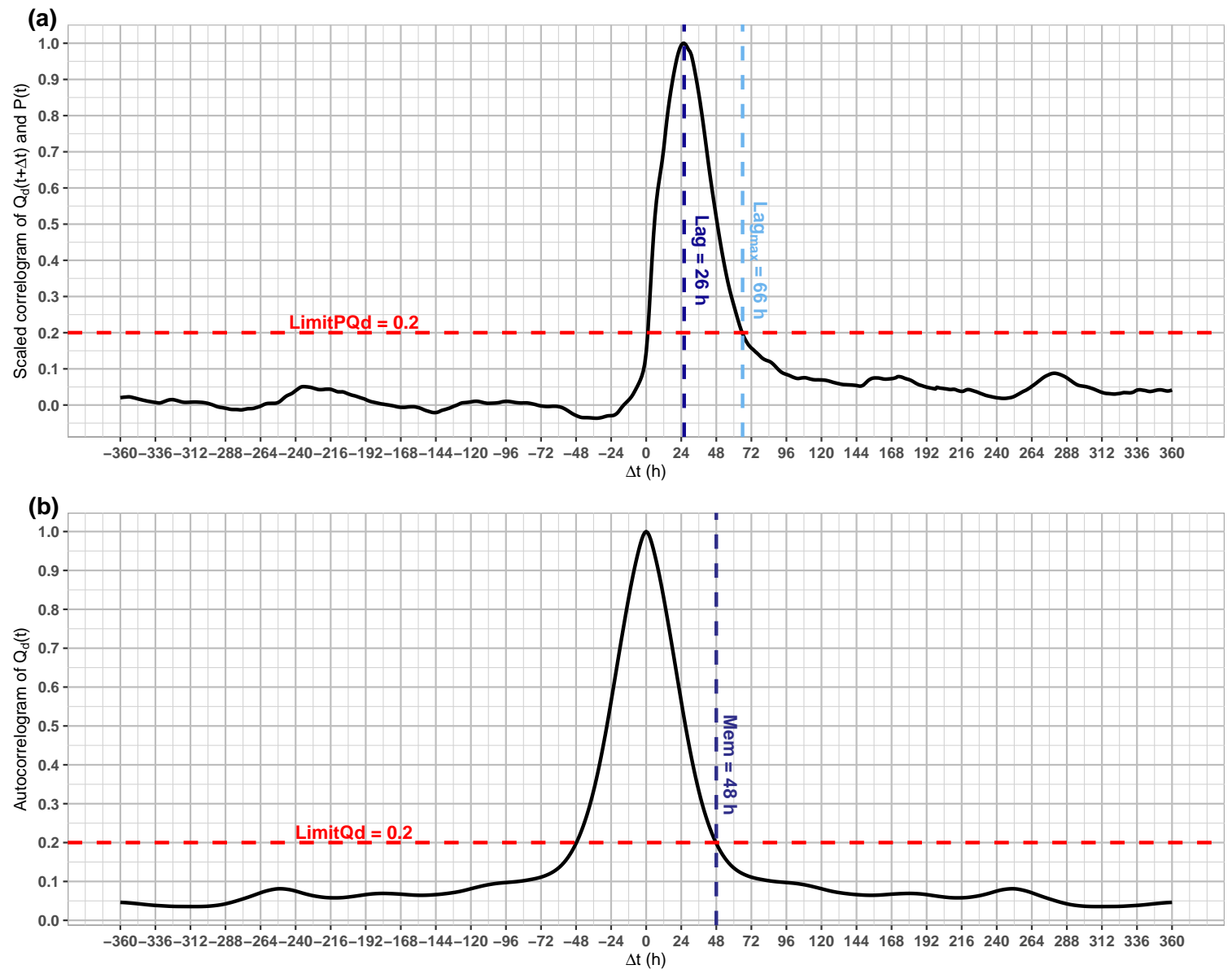

Figure 6. Examples of correlograms computed for the catchment drained by the USGS station 01658000 Mattawoman Creek near Pomonkey, Maryland, which has an area of $143.6 \mathrm{~km}^{2}$. (a) Scaled correlogram of hourly direct discharge $Q_{d}$ and hourly precipitation $P$, and (b) autocorrelogram of $Q_{d}$. 
Table 3. Summary of the steps of the event separation method.

\begin{tabular}{|c|c|}
\hline Steps & Settings \\
\hline Start of the event & $\begin{array}{l}\text { - } Q_{d}^{\text {start }}=\max \left(\frac{Q_{d}^{p}}{10}, 0.05 \cdot\left(Q_{d}^{p}-Q_{d}^{0}\right)\right) \text {, where } Q_{d}^{0} \text { is the minimum of } \\
Q_{d}(t) \text { for } t \in\left[t_{\text {peak }}-L a g-\operatorname{Lag}_{\text {max }}, t_{\text {peak }}\right] \text {, where } t_{\text {peak }} \text { is the peak } \\
\text { moment } \\
\text { - } T W_{\text {start }}=\left[t_{\text {peak }}-L a g-\operatorname{Lag}_{\text {max }}, t_{\text {peak }}\right] \\
\text { - } T W P_{\text {start }}=\left[t_{\text {deb }}-\operatorname{Lag}_{\text {max }}, t_{\text {deb }}\right], \text { where } t_{\text {deb }} \text { is the start moment }\end{array}$ \\
\hline End of the event & $\begin{array}{l}\text { - } Q_{d}^{\text {end }}=\max \left(\frac{Q_{d}^{p}}{10}, 0.05 \cdot\left(Q_{d}^{p}-Q_{d}^{1}\right)\right), \text { where } Q_{d}^{1} \text { is the minimum of } \\
Q_{d}(t) \text { for } t \in\left[t_{\text {peak }}, t_{\text {peak }}+\text { Mem }\right] \text {, where } t_{\text {peak }} \text { is the peak moment } \\
\text { - } T W_{\text {end }}=\left[t_{\text {peak }}, t_{\text {peak }}+\text { Mem }\right] \\
\text { - } p=50\end{array}$ \\
\hline Additional conditions & $\begin{array}{l}\text { - The ratio of baseflow to total flow at } t_{\text {peak }} \text { should be less than } B F I \\
\text { - No missing values are allowed } \\
\text { - Direct runoff depth should be less than the rainfall depth } \\
\text { - The rainfall depth should be higher than } 2 \mathrm{~mm} \\
\text { - Very short or very long events are eliminated (the event duration } \\
\text { should be between } 0.2 \cdot \mathrm{Mem} \text { and } 1.2 \cdot \mathrm{Mem} \text { ) }\end{array}$ \\
\hline
\end{tabular}

\section{Step 4: Determination of the end of the event}

As in step 3, a limit $Q_{d}^{\text {end }}$ function of $Q_{d}^{p}$ is determined. A time window $T W_{\text {end }}$ after the peak is screened to identify the moment when $Q_{d}(t)=Q_{d}^{e n d}$. The rainfall depth between the peak and the end should be less than $p \%$ of the rainfall depth between the start and the peak.

\section{Step 5: Additional conditions}

Once the start and the end of an event are determined, the event must satisfy the following conditions: (1) At the peak moment, the ratio of the baseflow to the total flow should be less than the whole-period baseflow index of the catchment BFI, estimated from the baseflow separation step; (2) The rainfall and direct runoff time series should not contain missing values between the start and the end of the event; (3) The sum of the event rainfall depth should be higher than $2 \mathrm{~mm}$; (4) The total volume of direct runoff should be less than the total volume of event rainfall (i.e., runoff ratio less than 1); and (5) The total duration of the event should be greater than $20 \%$ of $\mathrm{Mem}$ and less than $120 \%$ of $\mathrm{Mem}$.

Finally, event $R R$ is taken as the ratio of the direct runoff depth to the rainfall depth. Table 3 summarizes the steps and the corresponding thresholds. 


\section{B Equations of the soil moisture accounting reservoir ( $S M A R)$}

As a proxy for antecedent soil moisture $(A S M)$, we used the soil moisture accounting reservoir (SMAR) of the GR4H hourly model (Ficchì, Perrin, and Andréassian, 2019). Detailed equations are given in Figure 7. First, the hourly throughfall $P_{t h}$ is estimated using the equations under Step 1 (Figure 7), where $P$ is the hourly precipitation, $P E$ the hourly potential evapotranspiration, and $I$ the interception reservoir state. Second, when $P E$ is not satisfied solely by the interception reservoir content, a depth $A E_{s}$ is subtracted from the $S M A R$ (Step 2). Third, we estimated the proportion of $P_{t h}$ that feeds the $S M A R$, noted $P_{s}$, which represents the amount of water that is expected to satisfy the initial losses through soil storage. Fourth, a depth representing the percolation is removed from the SMAR. $P_{s}$ and $A E_{s}$ are both a function of the state of the reservoir $S$, and its maximum capacity $S_{\text {max }}$. Finally, the pre-event catchment $A S M$ is taken as the ratio $S / S_{\max }$ at the start of the event. This ratio varies between 0 and 1 , where a value of 0 indicates a completely dry condition, and 1 indicates a completely wet condition. 


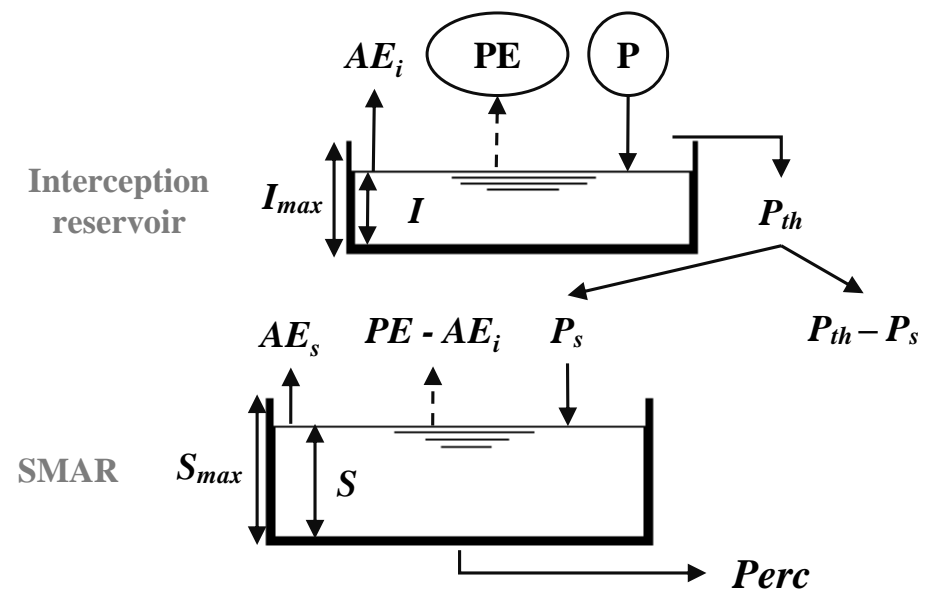

P: Precipitation

PE: Potential evapotranspiration

$\mathbf{A E _ { i }}, \mathbf{A E}_{\mathbf{s}}$ : Actual

evapotranspiration

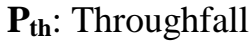

$\mathbf{P}_{\mathrm{s}}$ : Infiltration

Perc: Percolation

I: State of interception reservoir

$I_{\text {max: Interception reservoir }}$

maximum capacity

S: State of SMAR

$\mathbf{S}_{\max }$ : SMAR maximum capacity

Step 1: Estimation of throughfall $P_{\text {th }}$

1.1 $A E_{i}=\min (P E ; I+P)$

1.2 $I:=\max (0 ; I+P-P E)$

1.3 $P_{t h}=0$ if $I \leq I_{\max } / \quad P_{t h}=I-I_{\max }$ if $I>I_{\max }$

$1.4 \quad I:=I-P_{t h}$

Step 2: Subtraction of PE-induced losses

$$
A E_{S}=S * \frac{\left(2-\frac{S}{S_{\max }}\right) \tanh \left(\frac{P E-A E_{i}}{S_{\max }}\right)}{1+\left(1-\frac{S}{S_{\max }}\right) \tanh \left(\frac{P E-A E_{i}}{S_{\max }}\right)} ; \quad S:=S-A E_{S}
$$

Step 3: Feeding the SMAR

\section{Step 4: Subtraction of percolation}

$$
P_{s}=S_{\max } * \frac{\left(1-\left(\frac{S}{S_{\max }}\right)^{2}\right) \tanh \left(\frac{P_{t h}}{S_{\max }}\right)}{1+\frac{S}{S_{\max }} \tanh \left(\frac{P_{t h}}{S_{\max }}\right)} \quad ; \quad S:=S+P_{S}
$$

$$
\text { Perc }=S *\left(1-\left(1+\left(\frac{4}{21} \frac{S}{S_{\max }}\right)^{4}\right)^{-0.25}\right) \quad ; \quad S:=S-\operatorname{Perc}
$$

Figure 7. Description of the soil moisture accounting reservoir (SMAR) equations. All variables are in millimeters. The interception reservoir maximum capacity $I_{\max }$ was estimated by matching the flux of throughfall at the hourly and daily time steps (Ficchì, Perrin, and Andréassian, 2019). Daily throughfall was estimated by comparing daily $P$ with $P E$ (Perrin, Michel, and Andréassian, 2003). For the 852 catchments used in this study, $I_{\max }$ was between $2.00 \mathrm{~mm}$ and $4.00 \mathrm{~mm}$ with a median value of $2.75 \mathrm{~mm}$. $I$ is initiated at $0 \mathrm{~mm}$ whereas $S$ is initiated at $0.5 \cdot S_{\text {max }}$. 


\section{References}

Addor, N., et al. 2018. "A ranking of hydrological signatures based on their predictability in space". Water Resources Research 54 (11): 8792-8812. ISSN: 1944-7973. doi:10 .1029/2018WR022606. Cited on pages 2, 14.

Alley, W. M., and J. E. Veenhuis. 1983. "Effective impervious area in urban runoff modeling”. Journal of Hydraulic Engineering 109 (2):313-319. doi:10.1061/ (ASCE) 0733-9429 (1983) 109:2 (313) . Cited on page 23.

Anctil, F, et al. 2004. "A soil moisture index as an auxiliary ANN input for stream flow forecasting”. Journal of Hydrology 286 (1): 155-167. ISSN: 0022-1694. doi:10.1016/j.jhydrol.2003.09.006. Cited on pages 10, 21.

Ando, Y., K. Musiake, and Y. Takahasi. 1984. "Modelling of hydrologic processes in a small urbanized hillslope basin with comments on the effects of urbanization". Journal of Hydrology, Global Water: Science and Engineering The Ven Te Chow Memorial Volume, 68 (1): 61-83. ISSN: 0022-1694. doi:10.1016/0022-1694 (84) 90204 -X. Cited on page 2.

Baker, D. B., et al. 2004. "A new flashiness index: Characteristics and applications to midwestern rivers and streams". JAWRA Journal of the American Water Resources Association 40 (2): 503-522. ISSN: 1752-1688. doi:10 .1111/ j.1752-1688.200 4. tb01046.x. Cited on pages 6, 7 .

Beck, H. E., et al. 2018. "Present and future Köppen-Geiger climate classification maps at 1-km resolution”. Scientific Data 5 (1): 1-12. ISSN: 2052-4463. doi:10 .1038/sdata.2018.214. Cited on page 3.

Berghuijs, W. R., et al. 2016. “Dominant flood generating mechanisms across the United States”. Geophysical Research Letters 43 (9): 4382-4390. ISSN: 1944-8007. doi:10.1002/2016GL068070. Cited on page 2.

Berthet, L., et al. 2009. "How crucial is it to account for the antecedent moisture conditions in flood forecasting? Comparison of event-based and continuous approaches on 178 catchments”. Hydrology and Earth System Sciences 13 (6): 819-831. ISSN: 1027-5606. doi:10.5194/hess-13-819-2009. Cited on page 10.

Berthier, E., H. Andrieu, and J. D. Creutin. 2004. "The role of soil in the generation of urban runoff: development and evaluation of a 2D model”. Journal of Hydrology, Urban Hydrology, 299 (3): 252-266. ISSN: 0022-1694. doi:10 . $1016 /$ j. jhydrol. 2 004.08 .008 . Cited on page 23.

Blume, T., E. Zehe, and A. Bronstert. 2007. "Rainfall—runoff response, event-based runoff coefficients and hydrograph separation”. Hydrological Sciences Journal 52 (5): 843-862. ISSN: 0262-6667. doi:10 . 1623 / hys j . 52 . 5 . 84 3. Cited on pages $2,10,23,25$.

Bocinsky, R. K., D. Beaudette, and S. Chamberlain. 2019. FedData: Functions to automate downloading geospatial data available from several federated data sources. Visited on 05/21/2019. https : / CRAN. R-project. org/package=FedData. Cited on page 8.

Brabec, E., S. Schulte, and P. L. Richards. 2002. "Impervious surfaces and water quality: A review of current literature and its implications for watershed planning”. Journal of Planning Literature 16 (4): 499-514. ISSN: 0885-4122. doi:1 0.1177 / 0885 41202400903563. Cited on page 23 .

Breiman, L. 2001. “Random Forests”. Machine Learning 45 (1): 5-32. ISSN: 1573-0565. doi:10 . 1023 / A: 1010933404324. Cited on page 14

Brun, S. E., and L. E. Band. 2000. "Simulating runoff behavior in an urbanizing watershed". Computers, Environment and Urban Systems 24 (1): 5-22. ISSN: 0198-9715. doi:10.1016/S0198-9715 (99) 00040 -X. Cited on pages 2, 21.

Cappus, P. 1960. "Bassin expérimental d'Alrance. Étude des lois de l'écoulement. Application au calcul et la prévision des débits”. La Houille Blanche: 493-520. ISSN: 0018-6368, 1958-5551. doi:10 .1051/ I hb/1960007. Cited on page 10.

Cicco, L. A. D., et al. 2018. dataRetrieval: R packages for discovering and retrieving water data available from U.S. federal hydrologic web services. Reston, VA: U.S. Geological Survey. doi:10.5066/P 9X4L3GE. Cited on page 3.

Collischonn, W., and F. M. Fan. 2013. "Defining parameters for Eckhardt's digital baseflow filter”. Hydrological Processes 27 (18): 2614-2622. ISSN: 1099-1085. doi:10.1002 / hyp. 9391. Cited on pages 10, 25.

Debbage, N., and J. M. Shepherd. 2018. “The influence of urban development patterns on streamflow characteristics in the Charlanta Megaregion". Water Resources Research 54 (5): 3728-3747. ISSN: 1944-7973. doi:10 . 1029 / 2017 WR021594. Cited on page 23. 
Ebrahimian, A., B. N. Wilson, and J. S. Gulliver. 2016. "Improved methods to estimate the effective impervious area in urban catchments using rainfall-runoff data”. Journal of Hydrology 536:109-118. ISSN: 0022-1694. doi:10 . $1016 / j$. jhydrol.2 016.02 .023 . Cited on page 23.

Eckhardt, K. 2005. "How to construct recursive digital filters for baseflow separation". Hydrological Processes 19 (2): $507-515$. ISSN: 1099-1085. doi:10.1002/hyp. 5675. Cited on pages 10, 25.

Falcone, J. A. 2011. GAGES-II: Geospatial Attributes of Gages for Evaluating Streamflow. USGS Unnumbered Series. Reston, VA: U.S. Geological Survey. Visited on 07/23/2019. http: / / pubs. er.usgs.gov/publication/70046617. Cited on pages $3,7,23$.

FAO/IIASA/ISRIC/ISS-CAS/JRC. 2012. Harmonized world soil database. Tech. rep. FAO, Rome, Italy and IIASA, Laxenburg, Austria. Cited on page 8.

Ficchì, A., C. Perrin, and V. Andréassian. 2019. "Hydrological modelling at multiple sub-daily time steps: Model improvement via flux-matching”. Journal of Hydrology 575:1308-1327. ISSN: 0022-1694. doi:10 . 1016 / j . jhydrol .2019.05.084. Cited on pages 10, 28, 29.

Gao, H., et al. 2018. "Landscape heterogeneity and hydrological processes: a review of landscape-based hydrological models". Landscape Ecology 33 (9): 1461-1480. ISSN: 1572-9761. doi:10.1007/s10980-018-0690-4. Cited on page 23.

Gleeson, T., et al. 2014. “A glimpse beneath earth's surface: GLobal HYdrogeology MaPS (GLHYMPS) of permeability and porosity”. Geophysical Research Letters 41 (11): 3891-3898. ISSN: 0094-8276. doi:10 . 1002 / 2014 GL059856. Cited on page 9.

Graeff, T., et al. 2012. "Predicting event response in a nested catchment with generalized linear models and a distributed watershed model”. Hydrological Processes 26 (24): 3749-3769. ISSN: 1099-1085. doi:10 . 1002 / hyp . 8463 . Cited on page 2.

Heggen, R. J. 2001. “Normalized Antecedent Precipitation Index”. Journal of Hydrologic Engineering 6 (5): 377-381. ISSN: 1084-0699. doi:10.1061/(ASCE) 1084-0699(2001)6:5 (377). Cited on page 10.

Hewlett, J. D., J. C. Fortson, and G. B. Cunningham. 1977. "The effect of rainfall intensity on storm flow and peak discharge from forest land”. Water Resources Research 13 (2): 259-266. ISSN: 1944-7973. doi:10 .1029/WR013i 002 p00259. Cited on pages 2,23 .

Holko, L., et al. 2011. "Flashiness of mountain streams in Slovakia and Austria”. Journal of Hydrology 405 (3): 392-401. ISSN: 0022-1694. doi:10.1016/j.jhydrol.2011.05.038. Cited on pages 6, 7.

Homer, C., et al. 2015. "Completion of the 2011 National Land Cover Database for the Conterminous United States Representing a decade of land cover change information”. Photogrammetric Engineering \& Remote Sensing 81 (5): 345-354. ISSN: 0099-1112. doi:10.1016/S0099-1112(15) 30100-2. Cited on page 5.

Isik, S., et al. 2013. "Modeling effects of changing land use/cover on daily streamflow: An Artificial Neural Network and curve number based hybrid approach". Journal of Hydrology, Hydrology of peri-urban catchments: processes and modelling, 485:103-112. ISSN: 0022-1694. doi:10.1016/j.jhydrol.2012.08.032. Cited on page 10.

Javelle, P., et al. 2010. "Flash flood warning at ungauged locations using radar rainfall and antecedent soil moisture estimations". Journal of Hydrology, Flash Floods: Observations and Analysis of Hydrometeorological Controls, 394 (1): 267-274. ISSN: 0022-1694. doi:10.1016/j.jhydrol.2010.03.032. Cited on page 10.

Kirchner, J. W. 2009. "Catchments as simple dynamical systems: Catchment characterization, rainfall-runoff modeling, and doing hydrology backward”. Water Resources Research 45 (2). ISSN: 1944-7973. doi:10 . 1029/2008WR0 06912 . Cited on page 10 .

Kohler, M. A., and R. K. Linsley. 1951. Predicting the runoff from storm rainfall. Weather Bureau Research Papers. U.S. Department of Commerce, Weather Bureau. Cited on page 10.

Kursa, M. B., and W. R. Rudnicki. 2020. Boruta: Wrapper algorithm for all relevant feature selection. Visited on 10/06/2020. https: / / CRAN.R-project.org/package=Boruta. Cited on page 14.

— . 2010. "Feature selection with the Boruta package". Journal of Statistical Software 36 (1): 1-13. ISSN: 1548-7660. doi:10 . 18 637/ jss.v036. i11. Cited on page 14.

Liaw, A., and M. Wiener. 2002. "Classification and regression by randomForest". R News 2 (3): 18-22. ISSN: 1609-3631. Cited on page 14 . 
Lin, Y., and K. E. Mitchell. 2005. “The NCEP stage II/IV hourly precipitation analyses: Development and applications”. In Proceedings of the 19th conference on Hydrology, 9-13. Citeseer. Cited on page 3.

McGrane, S. J. 2016. "Impacts of urbanisation on hydrological and water quality dynamics, and urban water management: a review”. Hydrological Sciences Journal 61 (13): 2295-2311. ISSN: 0262-6667. doi:10 . 1080 / 02626667.2015 .1128084$. Cited on page 21 .

Mei, Y., and E. N. Anagnostou. 2015. "A hydrograph separation method based on information from rainfall and runoff records". Journal of Hydrology 523:636-649. ISSN: 0022-1694. doi:10 . 1016/ j . jhydrol . 2015 . 01 . 083. Cited on pages 10, 24, 25.

Mejía, A. I., and G. E. Moglen. 2010. "Impact of the spatial distribution of imperviousness on the hydrologic response of an urbanizing basin”. Hydrological Processes 24 (23): 3359-3373. ISsN: 1099-1085. doi:10 . 1002 / hyp . 7755. Cited on page 23.

Merz, R., G. Blöschl, and J. Parajka. 2006. “Spatio-temporal variability of event runoff coefficients”. Journal of Hydrology 331 (3): 591-604. ISSN: 0022-1694. doi:10.1016/j.jhydrol.2006.06.008. Cited on page 10.

Merz, R., and G. Blöschl. 2009. “A regional analysis of event runoff coefficients with respect to climate and catchment characteristics in Austria”. Water Resources Research 45 (1). ISSN: 1944-7973. doi:10 . 1029 /2008WR0 07163. Cited on pages $2,10,21,23,24$.

Miller, J. D., and T. Hess. 2017. “Urbanisation impacts on storm runoff along a rural-urban gradient”. Journal of Hydrology 552:474-489. ISSN: 0022-1694. doi:10.1016/j.jhydrol.2017.06.025. Cited on pages 2, 3, 21, 23.

Norbiato, D., et al. 2009. “Controls on event runoff coefficients in the eastern Italian Alps”. Journal of Hydrology 375 (3): 312-325. ISSN: 0022-1694. doi:10.1016/j.jhydrol.2009.06.044. Cited on pages 10, 24.

Oudin, L., et al. 2018. "Hydrological impacts of urbanization at the catchment scale". Journal of Hydrology 559:774-786. ISSN: 0022-1694. doi:10.1016/j. jhydrol.2018.02.064. Cited on page 23.

Oudin, L., et al. 2005. "Which potential evapotranspiration input for a lumped rainfall-runoff model?: Part 2-Towards a simple and efficient potential evapotranspiration model for rainfall-runoff modelling”. Journal of Hydrology 303 (1): 290-306. ISSN: 0022-1694. doi:10.1016/j.jhydrol.2004.08.026. Cited on page 7.

Perrin, C., C. Michel, and V. Andréassian. 2003. "Improvement of a parsimonious model for streamflow simulation”. Journal of Hydrology 279 (1): 275-289. ISSN: 0022-1694. doi:10 .1016/S0022-1694 (03) 00225-7. Cited on page 29.

Price, K. 2011. "Effects of watershed topography, soils, land use, and climate on baseflow hydrology in humid regions: A review". Progress in Physical Geography: Earth and Environment 35 (4): 465-492. ISSN: 0309-1333. doi:1 $0.1177 / 030913331140$ 2714. Cited on page 2.

Ragab, R., et al. 2003. "Experimental study of water fluxes in a residential area: 2. Road infiltration, runoff and evaporation". Hydrological Processes 17 (12): 2423-2437. ISSN: 1099-1085. doi:10.1002 / hyp.1251. Cited on page 23.

Ramier, D., E. Berthier, and H. Andrieu. 2011. “The hydrological behaviour of urban streets: long-term observations and modelling of runoff losses and rainfall-runoff transformation”. Hydrological Processes 25 (14): 2161-2178. ISSN: 1099-1085. doi:10.1002/hyp. 7968. Cited on page 23.

Read, J. S., et al. 2015. "geoknife: Reproducible web-processing of large gridded datasets”. Ecography. doi:10 . 1111 / ecog . 0 1880. Cited on pages 3, 6 .

Redfern, T. W., et al. 2016. "Current understanding of hydrological processes on common urban surfaces". Progress in Physical Geography: Earth and Environment 40 (5): 699-713. ISSN: 0309-1333. doi:10 . 1177 / 0309133316652819. Cited on page 23.

Saadi, M., L. Oudin, and P. Ribstein. 2019. "Random forest ability in regionalizing hourly hydrological model parameters". Water 11 (8): 1540. doi:10.3390/w11081540. Cited on page 3.

Salvadore, E., J. Bronders, and O. Batelaan. 2015. "Hydrological modelling of urbanized catchments: A review and future directions". Journal of Hydrology 529:62-81. ISSN: 0022-1694. doi:10 . 1016 / j . jhydrol . 2015.06.028. Cited on page 23.

Sillanpää, N., and H. Koivusalo. 2015. "Impacts of urban development on runoff event characteristics and unit hydrographs across warm and cold seasons in high latitudes”. Journal of Hydrology 521:328-340. ISSN: 0022-1694. doi:10 . $1016 / \mathrm{j}$. jh ydrol.2014.12.008. Cited on pages 21, 24. 
Smith, B. K., et al. 2013. “Spectrum of storm event hydrologic response in urban watersheds”. Water Resources Research 49 (5): 2649-2663. ISSN: 1944-7973. doi:10.1002/wrcr.20223. Cited on pages 2, 21.

Soulis, K. X., et al. 2009. "Investigation of the direct runoff generation mechanism for the analysis of the SCS-CN method applicability to a partial area experimental watershed”. Hydrology and Earth System Sciences 13 (5): 605-615. ISSN: $1027-5606$. doi:10.5194/hess-13-605-2009. Cited on page 10.

Survey, U. G. 1994. Nationwide summary of US Geological Survey regional regression equations for estimating magnitude and frequency of floods for ungaged sites, 1993. Water-Resources Investigations Report 94-4002. Reston, VA. Visited on 10/16/2020. doi:10.3133/wri 944002 . https://pubs.er.usgs.gov/publication/wri 944002 . Cited on page 2 .

Tarasova, L., et al. 2018a. "Exploring controls on rainfall-runoff events: 1. Time series-based event separation and temporal dynamics of event runoff response in Germany”. Water Resources Research 54 (10): 7711-7732. ISSN: 1944-7973. doi:10 10 29/2018WR022587. Cited on pages 2, 10, 23, 24, 25.

Tarasova, L., et al. 2018b. "Exploring controls on rainfall-runoff events: 2. Regional patterns and spatial controls of event characteristics in Germany”. Water Resources Research 54 (10): 7688-7710. ISSN: 1944-7973. doi:10 .1029/2018WR02258 8. Cited on pages 2, 23.

Thornton, P. E., et al. 2016. "Daymet: Daily surface weather data on a 1-km grid for North America, version 3". ORNL DAAC. doi:10.3334/ORNLDAAC/1328. Cited on pages 5, 7 .

Verdin, K. L. 2017. Hydrologic Derivatives for Modeling and Analysis-A new global high-resolution database. USGS Numbered Series 1053. Reston, VA: U.S. Geological Survey. Visited on 10/25/2018. http: / / pubs . er. usgs.gov/publication / ds 1053. Cited on page 8.

Vörösmarty, C. J., et al. 2010. “Global threats to human water security and river biodiversity”. Nature 467 (7315): 555-561. ISSN: 1476-4687. doi:10.1038/nature09440. Cited on page 2.

Yang, G., et al. 2011. "The impact of urban development on hydrologic regime from catchment to basin scales”. Landscape and Urban Planning 103 (2): 237-247. ISSN: 0169-2046. doi:10.1016/ j. landurbplan.2011.08.003. Cited on page 21.

Zhang, Y., and W. Shuster. 2014. "Impacts of spatial distribution of impervious areas on runoff response of hillslope catchments: Simulation study”. Journal of Hydrologic Engineering 19 (6): 1089-1100. ISSN: 1943-5584. doi:10 . 1061 / (ASCE) HE . 194 3-5584.0000905. Cited on pages 2, 21.

Zhang, Y., et al. 2018. "Predicting runoff signatures osing regression and hydrological modeling approaches”. Water Resources Research 54 (10): 7859-7878. ISSN: 1944-7973. doi:10 .1029/2018WR023325. Cited on page 14.

Zhou, Z., et al. 2017. "The complexities of urban flood response: Flood frequency analyses for the Charlotte metropolitan region”. Water Resources Research 53 (8): 7401-7425. ISSN: 1944-7973. doi:10.1002/2016WR019997. Cited on pages 2, 21. 
